\title{
Dynamic modeling and parameter analysis study on reversible solid oxide cells during mode switching transient processes
}

\author{
Wang, Chaoyang; Chen, Ming; Liu, Ming; Yan, Junjie
}

Published in:

Applied Energy

Link to article, DOI:

10.1016/j.apenergy.2020.114601

Publication date:

2020

Document Version

Peer reviewed version

Link back to DTU Orbit

Citation (APA):

Wang, C., Chen, M., Liu, M., \& Yan, J. (2020). Dynamic modeling and parameter analysis study on reversible solid oxide cells during mode switching transient processes. Applied Energy, 263, [114601].

https://doi.org/10.1016/j.apenergy.2020.114601

\section{General rights}

Copyright and moral rights for the publications made accessible in the public portal are retained by the authors and/or other copyright owners and it is a condition of accessing publications that users recognise and abide by the legal requirements associated with these rights.

- Users may download and print one copy of any publication from the public portal for the purpose of private study or research.

- You may not further distribute the material or use it for any profit-making activity or commercial gain

- You may freely distribute the URL identifying the publication in the public portal 


\title{
Dynamic modeling and parameter analysis study on reversible solid oxide cells during mode switching transient processes
}

\author{
Chaoyang Wang ${ }^{\mathrm{a}, \mathrm{b}}$, Ming Chen ${ }^{\mathrm{b} *}$, Ming Liu ${ }^{\mathrm{a}}$, Junjie Yan ${ }^{\mathrm{a}}$ \\ a State Key Laboratory of Multiphase Flow in Power Engineering, Xi'an Jiaotong University, Xi'an 710049, China \\ ${ }^{\mathrm{b}}$ Department of Energy Conversion and Storage, Technical University of Denmark, Roskilde DK-4000, Denmark
}

*Corresponding author. Email: minc@dtu.dk, Tel.: +45 46775757.

\section{GRAPHICAL ABSTRACT}

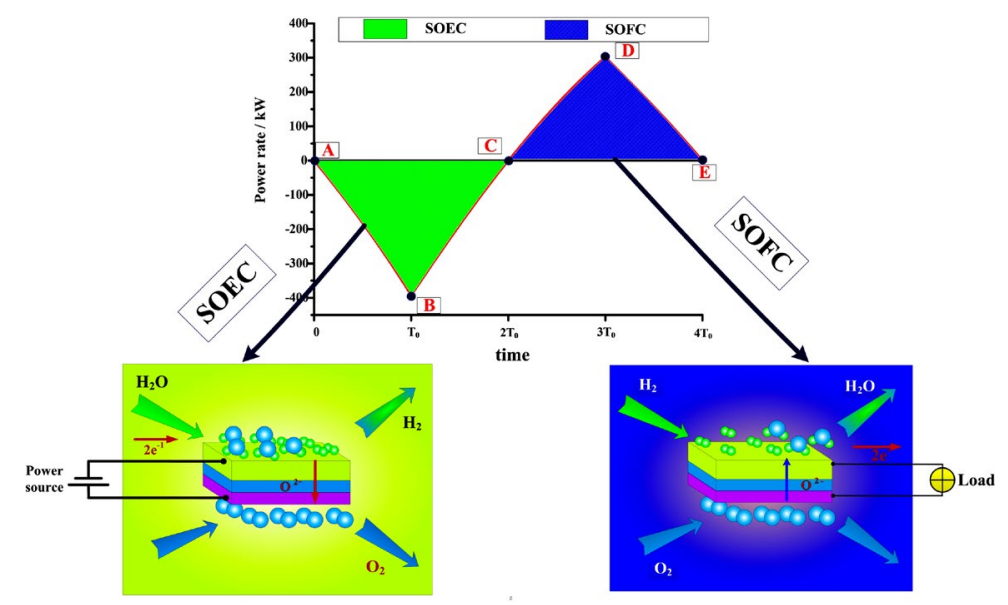

Reversible solid oxide cells mode switching between electrolysis and fuel cell operation

\begin{abstract}
Reversible solid-oxide cells (SOCs) are a promising technology for mitigating the fluctuation of power from renewable sources. Mode switching between electrolysis and fuel cells occurs frequently and is necessary for an SOC stack. Herein, a dynamic SOC-stack model was developed and validated against experimental data. Subsequently, we extensively studied the stack temperature $\left(T_{\mathrm{s}}\right)$, voltage $\left(V_{\mathrm{s}}\right)$, and reversible efficiency $\left(\eta_{\mathrm{re}}\right)$ with different designing and operating parameters, including stack heat capacity $\left(C_{\mathrm{s}}\right)$, inlet hydrogen fraction $\left(x_{\mathrm{H}_{2}}\right)$, stack operational pressure $(p)$, inlet work medium temperature $\left(T_{\text {in }}\right)$, current density $(I)$, and mode switching frequency $(f)$. For an actual SOC plant, the stack may work in a nearly adiabatic environment. Our calculation results show that with $x_{\mathrm{H}_{2}}$ increasing from 0.2 to 0.6 , the variation in $\Delta T_{\mathrm{s}}$ decreases by $25 \%, V_{\mathrm{s}}$ increases by $10 \%$, and $\eta_{\mathrm{re}}$ increases by $2.9 \%$. With fourfold increasing in $C_{\mathrm{S}}$ and $p, \Delta T_{\mathrm{s}}$ decreases by $75 \%$ and $25 \%$ and $\eta_{\mathrm{re}}$ increases by $0.47 \%$ and $1.8 \%$, respectively, whereas, $V_{\mathrm{s}}$ is nearly unaffected. $\Delta T_{\mathrm{s}}$ and $\Delta V_{\mathrm{s}}$ almost proportionally increase with $I$. In relation to $T_{\text {in }}$ or $f, \Delta T_{\mathrm{s}}$ is unaffected,
\end{abstract}


$\Delta V_{\mathrm{s}}$ decreases, and $\eta_{\mathrm{re}}$ slightly increases. Overall, this work identified the most critical stack designing and operating factors affecting the transient behavior of an SOC stack during mode switching processes. The results can serve as guidelines for SOC-stack design and operation-strategy optimization.

Keywords: Solid-oxide cell; Dynamic stack modeling; Energy storage; Mode switching operation; Transient operation; Reversible efficiency.

\section{Introduction}

To become independent of fossil fuels and protect the environment adequately, an increasing number of countries encourage the development of Renewable Energy Sources (RES) fueled power plants in recent years [1]. For example, Germany aims to increase the share of renewables to at least $80 \%$ of gross power consumption by 2050 [2], and Denmark has an ambitious goal of providing electricity and heat all from renewables by 2035 and realizing a fossil-free energy system by 2050 [3]. Power generated from RES, such as wind, solar, geothermal, and tidal resources, is intermittent or periodical and is often constrained by geography[4, 5]. To overcome these drawbacks, we need to develop electricity energy storage methods [6-8]. The reversible SOC plant is a promising approach to alleviate the unpredictability of power output from RES. Solid oxide cells attract many researchers to focus on their energy-conversion performances [9-11]. SOC plants can work in electrolysis mode to consume the excess electricity generated from RES to produce hydrogen (or carbon monoxide) and oxygen [12]. When power generation is in demand, SOC plants can work in the fuel cell mode to convert the stored fuel to electricity and heat. The reversible SOC stack is the core of the SOC plant [13]. Variations in stack performance during transient processes greatly influence energy storage and conversion efficiency. The temperature and voltage of the stack vary during mode switching. This process may further affect the degradation and lifetime of the stack. To uncover the energy-conversion process in SOC stacks and the operating factors of the stack bondaries control, researchers should consider dynamic stack modeling and parameter sensitive analysis.

Dynamic modeling is a cost-economic and effective way for exploring the transient behavior in research and industrial applications $[14,15]$. Many researchers pursued dynamic modeling of the SOC at different levels from a single repeating unit to a stack, and further to a standalone reversible system or integrated with other types of power plants. Considering the dynamic stack model, models at different dimensions were developed. An overview table summarizing the previous modeling efforts on reversible SOC or SOFC can be found in the paper by Bao et al. [16]. Extensive work has been done on modeling reversible SOCs. Hauck et al. [17] established a dynamic model based on Aspen Plus software. They concluded that the overall cell performance can be improved by increasing the 
operating pressure or temperature. Based on a 1D transient reversible SOC model, Srikanth et al. [18] proposed a strategy for the optimization of inlet work medium temperature to reduce the temperature variation rate during mode switching transient processes. Zheng et al. [19] presented a 1D dynamic model of a tubular SOC in radius direction. Based on the 1D model, the performance of the SOC during mode switching in the adiabatic environment was studied under step and continuous voltage variation. $\mathrm{Ni}$ [20] presented a 2D model to describe the thermal, electrochemical, reversible water gas shift reaction, and methanation reactions in SOCs [21]. Efforts have also been devoted to modeling solid oxide fuel cells (SOFC). Bhattacharyya et al. [22] studied the dynamic characteristics of the tubular SOFC. Salogni and Colonna [13] presented the development and validation of a nonlinear dynamic lumped model of a SOFC stack. Nikooyeh et al. [23] developed a 3D planar model of an internal reforming SOFC stack with a coflow configuration. The distribution of both temperature and gas composition through the gas channels and stack frames has been studied. Peksen et al. [24] elucidated a 3D thermo-mechanical analysis of a planar SOFC short stack over an entire thermal cycle. Chen et al. [25] presented a 2D thermal model of ethanol-fueled SOFCs and investigated the effects of stack operation conditions on carbon deposition and those of fuel inlet temperature on stack voltage. Some dynamic models have been developed from governing equations and numerical methods [13, 23-25]. Some of the complicated models were developed based on (Computational Fluid Dynamic) CFD software, such as FLUENT and COMSOL Multiphysics[26-30]. Qu et al. [26] developed a 3D dynamic model by using FLUENT. Their modeling results show that the geometry of the oxygen electrode side gas channel has a substantial effect on the oxygen distribution and thus on the overall cell performance. Al-Masri et al. [27] developed a 3D CFD model to predict the thermal performance of a planar SOFC stack and analyzed thermal stress under different operating conditions. Zhang et al. [28] developed a 3D model and studied the influence of different flow configurations (co-, counter- and cross-flow). Nerat and Juričić [29] developed a 3D model by using COMSOL Multiphysics. They identified the current density and inlet velocity of fuel gas as the key parameters for improving fuel utilization and conversion efficiency. Nishida et al. [30] presented an SOFC stack model with combined gas transport and electrochemistry. By using this model, they predicted performance of a stack tested in a furnace or used for in-field power generation.

Several studies have been devoted to SOC system modeling and configuration optimization [31,32]. Cheng et al. [31] investigated $10 \mathrm{~kW}$-scale SOFC-based systems. Four representative systems are compared in terms of their technical and exergoeconomic performance under identical net power output. Their work provides a theoretical foundation for the design, analysis, and application of SOFC systems. Safari et al. [32] presented a mathematical model of SOFC to simulate dynamic processes and damp low frequency oscillations by control optimization. Perna 
et al. [33] modeled a SOFC/MGT hybrid power plant for CHP and analyzed the effect of operation parameters.

The stack durability is another important factor for the SOC technology development. The stack durability under different operating conditions have been extensively studied to clarify the degradation mechanisms involved and counteract the degradation processes. Modeling efforts were also devoted to this area. Navasa et al. [34] developed a 3D multiphysics model of an SOEC cell to reveal the degradation process and explore the boundary conditions aimed at extending stack lifetime. Liu et al. [35] developed a mathematical model to estimate thermal stresses and predict cell lifetime.

At the system level, for standalone SOFC power systems or hybrid power systems, the modeling efforts focus on the optimization of system configuration or control strategies. Wen et al. [36, 37] developed an SOFC model and optimized the design and operational parameters to maximize the power output in steady-state work conditions. Li et al. [38] proposed a model predictive control strategy based on genetic optimization to meet the requirement for the desired fuel utilization and overcome the nonlinear predictive control constraints of the SOFC. Bang-Møller et al. [39] optimized a hybrid CHP plant via exergy analysis. Based on genetic algorithm, Habibollahzade et al. [40] optimized a hybrid SOC system considering the exergy efficiency, total product cost, levelized emissions, and hydrogen production rate. The control of the conditions for mode switching is another research focus. Jin and Xue [41] investigated the transient behavior of SOCs during mode switching in the current density range of $-0.16 \mathrm{~A} \mathrm{~cm}^{-}$ 2 to $0.17 \mathrm{~A} \mathrm{~cm}^{-2}$. Christopher et al. [42] analyzed the design and techno-economic aspects of reversible SOC systems for distributed energy storage.

Extensive work has been conducted on modeling SOCs with different dimensions from 0D to 3D according to the different research targets. However, most of the previously developed models are validated with experimental data obtained under steady state work conditions. For a dynamic stack, the model should also be validated for the mode switching processes. Previous efforts were devoted primarily to durability studies and optimization of operating parameters under steady-state work conditions. Studies on mode switching transient processes are rather limited. Accordingly, in the current work, a dynamic model of a reversible SOC stack was established and validated with experimental data obtained during mode switching transient processes. An adiabatic work environment was adopted for the stack. The influence of stack design and operation conditions on the stack performance (stack-temperature variation, power output, and efficiency) was studied in detail.

The present work is organized as follows. First, the dynamic model of the reversible SOC stack is presented and validated (Section 2), and the thermal analysis method of the stack during mode switching transient processes is presented (Section 3). Then, the influences of stack design and operation conditions on transient behavior are 
investigated (Section 4). The stack temperature, power output, and reversible efficiency during transient processes are discussed in detail (Section 5). Finally, concluding remarks are presented in Section 5. The current work provides new insights into the strategies to improve the efficiency and extend the lifetime of reversible SOC stacks.

\section{Dynamic modeling of a reversible SOC stack}

The dynamic model of an SOC stack includes a thermodynamic sub-model and an electrochemical sub-model, which are coupled together. In the fuel cell mode, SOC converts chemical energy into electricity and heat, whereas in electrolysis mode, it converts electricity and heat into chemical energy. The thermal states of the SOC affect electrochemistry and energy-conversion efficiency, and electrochemistry also influences stack temperature. The coupled relations among the fluid mechanics, thermodynamics, and electrochemistry are illustrated in Fig. 1.

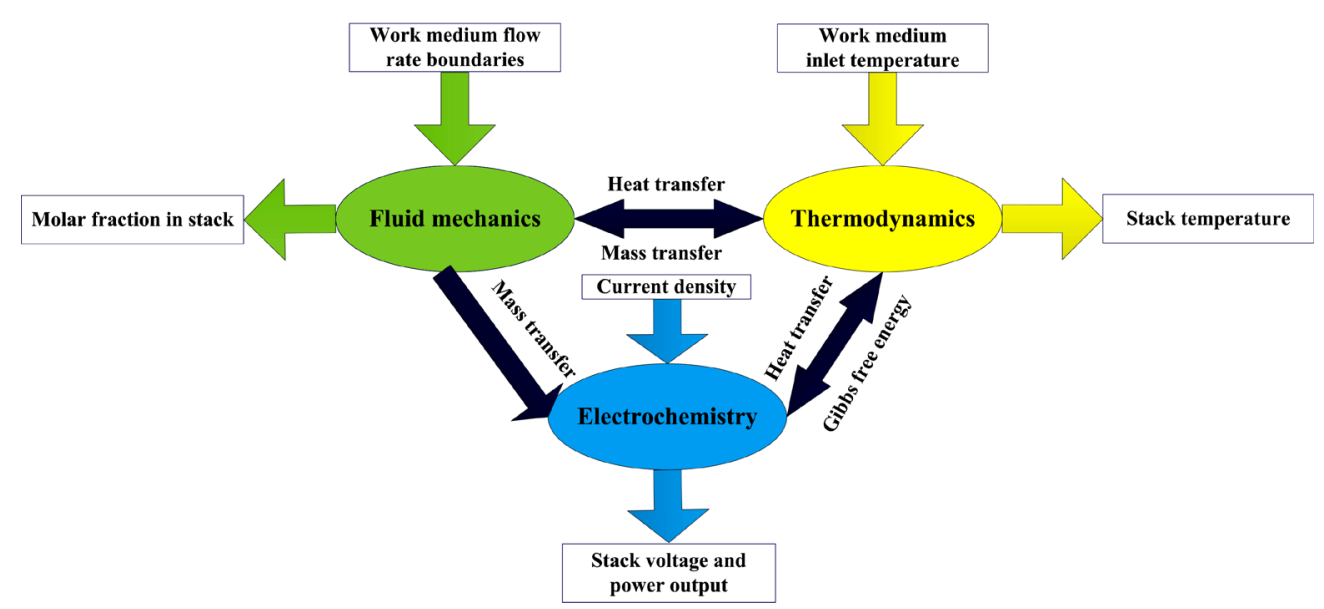

Fig. 1 Process diagram of the dynamic SOC-stack model developed in this work

For the dynamic model developed in this work, the following simplifications and assumptions were adopted:

(a) The work fluids are homogeneous and continuous;

(b) The lump parameter method is adopted for the SOC stack;

(c) Ideal gas properties are adopted for all the work gases;

(d) The mass of the stack itself is set as constant;

(e) The thermal inertia of the stack was primarily due from the solid structure, whereas the thermal inertia of the work medium stored in the stack (i.e., gases) is very low compared with that of the solid structure and hence can be neglected.

\subsection{Electrochemical model of the SOC}

Electrochemical reactions occur at the three-phases boundaries (TPB), which are basically interfaces formed by the electrocatalyst, electrolyte, and gas-phase boundaries [43]. The output voltage of the SOC can be described by 
Eq. (1) [44] as follows:

$$
\begin{aligned}
& V_{\text {cell }}=E-V_{\text {act }}-V_{\text {ohm }}-V_{\text {diffu }}, \\
& V_{\mathrm{s}}=N \cdot V_{\text {cell }}
\end{aligned}
$$

where $V_{\text {cell }}$ stands for the output voltage of the single cell, V; $E$ signifies the cell thermodynamic voltage (i.e., Nernst Potential), V; $V_{\text {act }}$ denotes the cell activation loss, $\mathrm{V} ; V_{\text {ohm }}$ refers to the cell ohmic loss, $\mathrm{V} ; V_{\text {diffu }}$ refers to the cell diffusion loss, $\mathrm{V} ; V_{\mathrm{s}}$ is the output voltage of the stack, $\mathrm{V}$; and $N$ denotes the number of the single repeating unit.

\section{i. Thermodynamic voltage}

The thermodynamic voltage of the single cell is the ideal voltage from the change in Gibbs free energy during the electrochemical reactions [45]. This parameter is defined by the Nernst equation in Eq. (2) as follow:

$$
\begin{aligned}
& E=-\frac{\Delta G^{0}}{2 F}+\frac{R \cdot T_{\mathrm{s}}}{2 F} \ln \left(\frac{p_{\mathrm{H}_{2}} \sqrt{p_{\mathrm{O}_{2}}}}{p_{\mathrm{H}_{2} \mathrm{O}}}\right), \\
& \Delta G^{0}=G_{\mathrm{H}_{2} \mathrm{O}}^{0}-\left(G_{\mathrm{H}_{2}}^{0}+\frac{1}{2} G_{\mathrm{O}_{2}}^{0}\right),
\end{aligned}
$$

where $\Delta G^{0}$ stands for Gibbs free-energy change of the reaction, $\mathrm{J} \mathrm{mol}^{-1} ; F$ is the Faraday constant, $96485 \mathrm{C} \mathrm{mol}^{-1}$; $R$ is the universal gas constant, $8.314 \mathrm{~J} \mathrm{~mol}^{-1} \mathrm{~K}^{-1} ; T_{\mathrm{s}}$ is the reaction temperature, $\mathrm{K}$; and $p_{\mathrm{H}_{2}}, p_{\mathrm{O}_{2}}$, and $p_{\mathrm{H}_{2} \mathrm{O}}$ are the partial pressures of hydrogen, oxygen, and steam in bar, respectively.

\section{ii.Activation loss}

In this work, the activation losses from both anode and cathode are considered separately. Butler-Volmer equation (BV) is one of the most fundamental relationships in electrochemical kinetics [46]. As shown in Eq. (4), BV describes how the electrical current of an electrode is determined by the electrode potential. For the modeling of SOCs, it is a semi-empirical method for evaluating the activation loss. The term $j_{0}$ represents the exchange current density, $\mathrm{A} \mathrm{cm}^{-2}$. The subscript $i$ represents the anode or cathode.

$$
j=j_{0, \mathrm{i}} \cdot\left(\exp \left(\frac{(1-\beta) F V_{\text {act,i }}}{R T_{\mathrm{c}}}\right)-\exp \left(\frac{-\beta F V_{\text {act, } \mathrm{i}}}{R T_{\mathrm{c}}}\right)\right),
$$

$\beta$ is the symmetry factor, which varies from 0.25 to 0.5 . To simplify the expression of the activation loss, we set $\beta$ to $0.5 . V_{\text {act,i }}$ can be reformulated as in Eq. (5) as follows:

$$
\begin{gathered}
V_{\text {act,i }}=\frac{R \cdot T_{\mathrm{c}}}{F \cdot n_{\mathrm{i}} \cdot \alpha} \sin \mathrm{h}^{-1}\left(\frac{j}{2 j_{0, \mathrm{i}}}\right), \\
j_{0, \mathrm{i}}=\gamma_{\mathrm{i}} \exp \left(-\frac{E_{\mathrm{act}, \mathrm{i}}}{R \cdot T_{\mathrm{c}}}\right),
\end{gathered}
$$


For the total activation loss of the single cell, $V_{\text {act }}$ can be formulated as in Eq. (7) as follows:

$$
V_{\mathrm{act}}=\frac{R \cdot T_{\mathrm{c}}}{F \cdot n_{\mathrm{a}} \cdot \alpha} \sinh ^{-1}\left(\frac{j}{2 j_{0, \mathrm{a}}}\right)+\frac{R \cdot T_{\mathrm{c}}}{F \cdot n_{\mathrm{c}} \cdot \alpha} \sinh ^{-1}\left(\frac{j}{2 j_{0, \mathrm{c}}}\right),
$$

where $\alpha$ is the transfer coefficient; $n$ is the number of transferred electrons during the chemical reaction; $j$ is the current density of the cell, $\mathrm{A} \mathrm{cm}^{-2} ; \gamma$ is the pre-exponential factor, $\mathrm{A} \mathrm{cm}^{-2}$; and $E_{\text {act }}$ is the activation energy, $\mathrm{J} \mathrm{mol}^{-1}$.

\section{iii.Ohmic loss}

Ohmic loss accounts for the voltage drop due to resistance to charge transport [18], including the electric charge transport and the ionic current of $\mathrm{O}^{2-}$ through the electrolyte layer. The resistance due to ions traveling through the electrolyte dominates the total ohmic loss, and the resistance for electrons to travel through the electrodes is neglected in our model [17]. The overpotential due to ohmic loss is a product of current density and the ohmic part of the area specific resistance ( $\mathrm{ASR}_{\mathrm{ohm}}$ ) as given by Eq. (8).

$$
V_{\text {ohm }}=j \cdot \mathrm{ASR}_{\text {ohm }},
$$

$\mathrm{ASR}_{\text {ohm }}$ is the total resistance to the charge transport and is calculated using Eq. (9). This parameter is divided into two parts. The first term in Eq. (9) represents the resistance due to the electrolyte, whereas the second term includes the resistance for the rest of the stack components, such as interconnects, current collectors, and protective layers[18]. The conductivity of the second item is a function of temperature, and its electrical resistance is much smaller than that of the electrolyte layer. The second item can be regarded as constant [17].

$$
\begin{aligned}
& \mathrm{ASR}_{\mathrm{ohmic}}=\frac{\delta_{\mathrm{el}}}{\sigma_{\mathrm{el}}}+r_{\mathrm{sc}}, \\
& \sigma_{\mathrm{el}}=\sigma_{0} \cdot \exp \left(\frac{-E_{\mathrm{act}, \mathrm{el}}}{R \cdot T_{\mathrm{S}}}\right),
\end{aligned}
$$

where $r_{\mathrm{sc}}$ is the constant term of ohmic resistance for one single repeating unit (SRU) at steady state, excluding the contribution from the cell, $\Omega \mathrm{cm}^{2} ; \delta_{\mathrm{el}}$ is the thickness of the electrolyte layer, $\mathrm{cm}$; and $\sigma_{\mathrm{el}}$ is the conductivity of the electrolyte material, $\Omega^{-1} \mathrm{~cm}^{-1}$.

\section{iv.Diffusion loss}

Electrochemical reactions occur at the electrolyte-electrode interfaces [18]. The concentration gradient across the electrodes leads to diffusion loss. Different models have been utilized to model the mass transport in SOC reactors, such as Fick's Model, the Stefan-Maxwell Model and the Dusty Gas Model (DGM) [47-49]. Suwanwarangkul et al. compared these three different models [49]. Among these models, the DGM model has the highest accuracy. However, an analytical solution is difficult to obtain when adopting DGM, and it requires a numerical solution for solving differential equations. This characteristics increases computational effort/time and becomes unfavorable, especially 
for simulating transient operations [50]. In this work, Fick's model is adopted for simulating gas diffusion. Equation (11) shows that the reversible voltage depends on the reactant and product concentration $[7,17,18]$.

$$
\begin{array}{r}
V_{\text {diffu }}=V_{\text {diffu,fuel }}+V_{\text {diffu,oxygen }}, \\
V_{\text {diffu,fuel }}=\frac{R \cdot T_{\mathrm{c}}}{2 \cdot F} \ln \left(\frac{p_{\mathrm{H}_{2} \mathrm{O}, \mathrm{ppb}} \cdot p_{\mathrm{H}_{2}, \text { bulk }}}{p_{\mathrm{H}_{2} \mathrm{O}, \text { bulk }} \cdot p_{\mathrm{H}_{2}, \mathrm{tpb}}}\right), \\
V_{\text {diffu,oxygen }}=\frac{R \cdot T_{\mathrm{c}}}{2 \cdot F} \ln \left(\frac{p_{\mathrm{O}_{2}, \text { bulk }}}{p_{\mathrm{O}_{2}, \mathrm{tpb}}}\right),
\end{array}
$$

where $p_{\mathrm{i}, \mathrm{bulk}}$ and $p_{\mathrm{i}, \mathrm{pb}}$ are the partial pressures of the species in the bulk flow and at TPB, Pa. The partial pressure at the TPB can be obtained using the Fick diffusion law [45] as follows:

$$
p_{\mathrm{i}, \mathrm{pb}}=p_{\mathrm{i}, \mathrm{bulk}}-\frac{R \cdot T_{\mathrm{s}} \cdot \delta_{i} \cdot j}{n_{i} \cdot F \cdot D_{\mathrm{eff}, \mathrm{i}}},
$$

where $D_{\text {eff,i }}$ is the effective diffusion coefficient for species $i$ in the porous electrode, $\mathrm{m}^{2} \mathrm{~s}^{-1}$, and it is a function of the electrode porosity $\varepsilon$ and tortuosity $\tau$. $D_{\text {eff,i }}$ can be obtained with the Bruggeman's correction [45], which is expressed as follows:

$$
D_{\mathrm{eff}, \mathrm{i}}=\frac{\varepsilon}{\tau} \frac{D_{\mathrm{Kn}, \mathrm{i}} \cdot D_{\mathrm{i}-\mathrm{j}}}{D_{\mathrm{Kn}, \mathrm{i}}+D_{\mathrm{i}-\mathrm{j}}},
$$

where $D_{\mathrm{Kn}, \mathrm{i}}$ and $D_{\mathrm{i}-\mathrm{j}}$ are the Knudsen and binary diffusion terms, respectively [51]. The Knudsen term describes the diffusion in porous media and can be expressed as follows:

$$
D_{\mathrm{Kn}, \mathrm{i}}=\frac{d_{p}}{3} \sqrt{\frac{8 \cdot R \cdot T_{\mathrm{c}}}{\pi M_{i}}},
$$

where $d_{\mathrm{p}}$ is the pore diameter, $\mathrm{m}$; and $M_{\mathrm{i}}$ is the molecular weight of the species, $\mathrm{g} \mathrm{mol}^{-1}$. The binary diffusion coefficient $D_{\mathrm{i}-\mathrm{j}}$ describes the diffusivity of two species within each other. Good agreement between the Fuller's correlation and measurements has been reported in Solheim's report [52]. In this paper, the parameter can be calculated using the Fuller equation, which is expressed as follows:

$$
D_{\mathrm{i}-\mathrm{j}}=\frac{1.43 \cdot 10^{-7} \cdot T_{\mathrm{c}}^{1.75}}{p \cdot \sqrt{\frac{2}{M_{i}^{-1}+M_{j}^{-1}}}\left(V_{d, i}^{\frac{1}{3}}+V_{d, j}^{\frac{1}{3}}\right)^{2}},
$$

where $p$ is the gas pressure, bar; and $V_{\mathrm{d}, \mathrm{i}}$ and $V_{\mathrm{d}, \mathrm{j}}$ are the diffusion volumes of the investigated species, $\mathrm{m}^{3}$. Their values are provided in Table 1. 
Table 1 Diffusion volume of gas species from literature [53]

\begin{tabular}{cc}
\hline Gas species & Diffusion volume \\
\hline $\mathrm{H}_{2}$ & 6.12 \\
$\mathrm{~N}_{2}$ & 18.5 \\
$\mathrm{O}_{2}$ & 16.3 \\
$\mathrm{H}_{2} \mathrm{O}$ & 13.1 \\
\hline
\end{tabular}

\subsection{Thermodynamic model of the stack}

When developing a dynamic stack model, the stack including the cells, interconnects and sealants and the work medium are considered separately.

For the work fluid, a lumped parameter method is adopted to model each control volume. In the control volume for the work medium, the mass and momentum governing equations are expressed in Eqs. (17)-(19).

$$
\begin{gathered}
\frac{d M_{\mathrm{i}}}{d \tau}=\dot{m}_{\mathrm{in}, \mathrm{i}}+\phi \cdot \dot{m}_{\mathrm{chem}, \mathrm{i}}-\dot{m}_{\mathrm{out}, \mathrm{i}}, \\
\dot{m}_{\mathrm{chem}, \mathrm{i}}=\frac{j \cdot N \cdot A_{\text {cell }}}{n \cdot F}, \\
R_{r} \cdot \dot{m}_{\text {out total }}^{2}=p_{\text {in }}-p_{\text {out }}, \\
p_{\text {in }, \mathrm{i}} \cdot V=M_{i} \cdot R \cdot T_{i}, \\
p_{\text {in }}=\sum_{i=1}^{7} p_{\text {in }, \mathrm{i}}, \\
\dot{m}_{\text {out total }}=\sum_{i=1}^{7} \dot{m}_{\text {out }, \mathrm{i}},
\end{gathered}
$$

where $M$ signifies the total molar quantity of the work fluid, mol; $\dot{m}$ denotes the molar flow rate of the work fluid, mol s${ }^{-1} ; j$ is the current density, $\mathrm{A} \mathrm{cm}^{-2} ; n$ is the number of electrons transferred in the electrochemical reaction; $\tau$ represents time, $\mathrm{s} ; p_{\text {in }}$ refers to the work fluid pressure, $\mathrm{MPa} ; p_{\text {out }}$ refers to the outlet boundary, $\mathrm{MPa}$; and $R_{\mathrm{r}}$ is the flow resistance coefficient of a gas channel, $\mathrm{kg}^{-2} \mathrm{MPa} \mathrm{s} \mathrm{s}^{2} . \phi$ is the sign for production $(+1)$ or consumption $(-1) . i$ from 1 to 7 represent the gas species, namely, $\mathrm{H}_{2}, \mathrm{O}_{2}, \mathrm{H}_{2} \mathrm{O}, \mathrm{N}_{2}, \mathrm{CH}_{4}, \mathrm{CO}$, and $\mathrm{CO}_{2}$ [45]. In the current work, only $\mathrm{H}_{2}$, $\mathrm{O}_{2}$, and $\mathrm{H}_{2} \mathrm{O}$ are involved.

For the stack frame, the mass remains constant. The energy conservation governing equations are shown in Eq. (20). The terms on the right side of the equal sign are the enthalpy change of the work medium throughout the stack, the heat released or absorbed from chemical reactions, the electrical power generated or consumed by the stack, and the heat absorbed from or released to the environment [54]. We assumed that the work fluid (gas) is the ideal gas and that the work medium enthalpy is a function of temperature only. The physical properties of the work medium are obtained from literature. 


$$
\begin{gathered}
C_{\mathrm{s}} M_{\mathrm{s}} \frac{d T_{\mathrm{c}}}{d \tau}=\dot{m}_{\mathrm{in}, \mathrm{i}} \dot{h}_{\mathrm{in}, \mathrm{i}}-\dot{m}_{\mathrm{out}, \mathrm{i}} \dot{h}_{\mathrm{out}, \mathrm{i}}+\phi \cdot \dot{m}_{\mathrm{chem}, \mathrm{i}} \dot{h}_{\mathrm{out}, \mathrm{i}}-\dot{W}+\frac{j N A_{\text {cell }}}{2 F} \cdot \dot{Q}_{\mathrm{react}}+\dot{Q}_{\mathrm{ext}}+\dot{Q}_{\mathrm{int}}, \\
\dot{W}=N \cdot V_{\mathrm{cell}} \cdot j \cdot A_{\mathrm{cell}}, \\
\dot{Q}_{\mathrm{ext}}=\sigma \cdot\left(T_{\mathrm{f}}^{4}-T_{\mathrm{s}}^{4}\right) \cdot A_{\mathrm{sur}}, \\
\dot{Q}_{\mathrm{int}}=j \cdot A_{\mathrm{cell}} \cdot\left(V_{\mathrm{act}}+V_{\mathrm{ohm}}\right)-j \cdot A_{\text {cell }} \cdot \frac{T_{\mathrm{c}} \cdot \Delta S^{0}}{2 F}, \\
\Delta S^{0}=\Delta S_{\mathrm{H}_{2} \mathrm{O}}^{0}-\left(\Delta S_{\mathrm{H}_{2}}^{0}+\frac{1}{2} \Delta S_{\mathrm{O}_{2}}^{0}\right)
\end{gathered}
$$

where $h$ is the work fluid enthalpy, $\mathrm{J} \mathrm{mol}^{-1} ; \dot{W}$ stands for the power of the reversible SOC, W; $\dot{Q}_{\text {react }}$ is the generation heat rate of the reaction for $\mathrm{H}_{2}(\mathrm{~g})+0.5 \mathrm{O}_{2}(\mathrm{~g})=\mathrm{H}_{2} \mathrm{O}(\mathrm{g}), \mathrm{W} \mathrm{mol}^{-1} ; A_{\text {cell }}$ is the active area of a single cell, $\mathrm{cm}^{2} ; A_{\text {sur }}$ is the surface area of the stack, $\mathrm{cm}^{2} ; \sigma$ stands for the Stefan-Boltzmann constant, $\mathrm{W} \mathrm{m}^{-2} \mathrm{~K}^{-4}$, and $\Delta S^{0}$ is the entropy of the reaction for $\mathrm{H}_{2}(\mathrm{~g})+0.5 \mathrm{O}_{2}(\mathrm{~g})=\mathrm{H}_{2} \mathrm{O}(\mathrm{g})$, W K $\mathrm{Kol}^{-1}$.

\subsection{Validation of the coupled dynamic model}

The coupled dynamic model was validated with experimental stack test data obtained at the Technical University of Denmark [55]. The stack was an 8-cell experimental stack of 2014-design produced by Topsoe Fuel Cell (TOFC). The cells are planar type Nickel/yttria stabilized zirconia (Ni/YSZ) electrode supported cells from the same production batch. Each cell is composed of a Ni/YSZ support and active fuel electrode, an YSZ electrolyte, and a strontium and cobalt co-doped lanthanum ferrite/gadolinia doped ceria oxygen electrode with a barrier layer between the electrolyte and the oxygen electrode. The cells have a footprint of $12 \times 12 \mathrm{~cm}^{2}$ with an active area of $87.7 \mathrm{~cm}^{2}$. The interconnect (IC) between every two cells was made of Crofer22APU with protective coating on both sides. The experimental stack was operated in a closed furnace. The supplied work gases are $\mathrm{H}_{2} \mathrm{O} / \mathrm{H}_{2}(50 / 50)$ for fuel electrode and pure $\mathrm{O}_{2}(100 \%)$ for oxygen electrode. To monitor the stack temperature, eight temperature probes (thermocouples) were inserted into the stack end-plates. Voltage probes in contact with the IC plates were used to monitor the voltage over each SRU, including the contributions from the cell, the IC, and the contact between them. The overall stack voltage can be obtained by summing up the eight SRU voltages and the voltages between the stack end-plates (top- or bottom-plate) and the top or bottom SRU. In the current work, the $I-V$ curves at $1073 \mathrm{~K}$ (stack temperature), in which $\mathrm{H}_{2} \mathrm{O} / \mathrm{H}_{2}$ (50/50) was fed to the $\mathrm{Ni} / \mathrm{YSZ}$ electrode compartment, were used to validate the stack model. The average stack temperature and SRU voltage were adopted to validate the coupled dynamic model. Notably, a full-sized Delta stack produced by TOFC at that time included 50 SRUs. In 2014, Topsoe introduced a nextgeneration stack design Topsoe Stack Platform (TSP). The new design addresses several issues related to the Delta design, such as larger cell active area, lower degradation rates, and improved robustness of the new design. Data 
demonstrating the improved performance and robustness of the TSP stack are available [56].

The fitted model parameters for the SOC cell and the stack are summarized in Tables 2 and 3, respectively. The flow rate and temperature of the inlet gases are listed in Table 4. The furnace temperature and the atmospheric pressure $(1 \mathrm{~atm})$ were used as the boundary condition. In the experimental stack testing, the steam was produced by burning $\mathrm{H}_{2}$ and $\mathrm{O}_{2}$ in a reactor outside the stack. This reaction enthalpy was partly supplied to the stack and partly released to the environment. This part of heat was considered as a source term in the energy governing equation. However, the exact amount is difficult to quantify, resulting in a small difference between the measured and simulated stack temperature as shown later in this paper. Experimental stack testing data with a different way of generating steam is needed to further calibrate the model, and this testing data will be considered in our future work.

Table 2 Fitting parameters of the SOC cell

\begin{tabular}{|c|c|c|c|}
\hline Parameter & Definition & Value and Unit & References/ notes \\
\hline$r_{\mathrm{sc}}$ & Constant ohmic resistance term & $5.70 \times 10^{-2} / \Omega \cdot \mathrm{cm}^{2}$ & At $1073 \mathrm{~K}$ \\
\hline$\sigma_{0}$ & $\begin{array}{l}\text { Pre-exponential factor for the ionic } \\
\text { conductivity of the electrolyte }\end{array}$ & $3.33 \times 10^{2} / \Omega^{-1} \cdot \mathrm{cm}^{-1}$ & {$[17]$} \\
\hline$E_{\text {act,fuel }}$ & Fuel electrode activation energy & $1.00 \times 10^{5} / \mathrm{J} \mathrm{mol}^{-1}$ & {$[17]$} \\
\hline$E_{\text {act,el }}$ & Electrolyte activation energy & $8.56 \times 10^{4} / \mathrm{J} \mathrm{mol}^{-1}$ & {$[17]$} \\
\hline$E_{\text {act,oxygen }}$ & Oxygen electrode activation energy & $1.00 \times 10^{5} / \mathrm{J} \mathrm{mol}^{-1}$ & {$[17]$} \\
\hline$\delta_{\text {fuel }}$ & Fuel electrode thickness & $1.50 \times 10^{-5} / \mathrm{m}$ & [34] \\
\hline$\delta_{\mathrm{el}}$ & Electrolyte thickness & $1.50 \times 10^{-5} / \mathrm{m}$ & [34] \\
\hline$\delta_{\text {oxygen }}$ & Oxygen electrode thickness & $3.00 \times 10^{-5} / \mathrm{m}$ & {$[34]$} \\
\hline$A_{\text {cell }}$ & Active area of single cell & $8.77 \times 10^{1} / \mathrm{cm}^{2}$ & \\
\hline$d_{\mathrm{p}}$ & Pore diameter & $2.00 \times 10^{-6} / \mathrm{m}$ & [17] \\
\hline$\gamma_{\text {fuel }}$ & Pre-exponential factor & $1.34 \times 10^{6} / \mathrm{A} \mathrm{cm}^{-2}$ & {$[17]$} \\
\hline$\gamma_{\text {oxygen }}$ & Pre-exponential factor & $2.05 \times 10^{5} / \mathrm{A} \mathrm{cm}^{-2}$ & [17] \\
\hline$\varepsilon$ & Electrode porosity & $3.00 \times 10^{-1}$ & {$[17]$} \\
\hline$\tau$ & Electrode tortuosity & $5.00 \times 10^{0}$ & [17] \\
\hline
\end{tabular}


Table 3 Fitting parameters of the SOC stack

\begin{tabular}{lll}
\hline Parameter & Definition & Value and unit \\
\hline$c_{\mathrm{s}}$ & Average specific heat capacity of the stack & $5.00 \times 10^{2} / \mathrm{J} \mathrm{kg}^{-1} \mathrm{~K}^{-1}$ \\
$M_{\mathrm{s}}$ & Mass of the stack & $3.70 \times 10^{1 / \mathrm{kg}}$ \\
$N$ & Number of SRU & $8.00 \times 10^{0}$ \\
$A_{\text {sur }}$ & Surface area of the stack & $7.00 \times 10^{-2} / \mathrm{m}^{2}$ \\
$\sigma$ & Stefan-Boltzmann constant & $5.67 \times 10^{-8} / \mathrm{W} \mathrm{m}^{-2} \mathrm{~K}^{-4}$ \\
$R_{\mathrm{r}}$ & Flow resistance coefficient & $1.00 \times 10^{0} / \mathrm{kg}^{-2} \mathrm{MPa} \mathrm{s}^{2}$ \\
$T_{\mathrm{f}}$ & Furnace temperature & $1.033 \times 10^{3} / \mathrm{K}^{2}$ \\
$T_{\mathrm{s}, \text { initial }}$ & Initial stack temperature & $1.073 \times 10^{3} / \mathrm{K}$ \\
\hline
\end{tabular}

Table 4 Input gases to the experimental stack

\begin{tabular}{lccc}
\hline & Gas & Flowrate/ $\mathrm{sccm} \mathrm{cm}^{-2}$ & Inlet temperature/K \\
\hline Hydrogen electrode side & $\mathrm{H}_{2} / \mathrm{H}_{2} \mathrm{O}(50: 50)$ & 12.44 & 1033 \\
Oxygen electrode side & $\mathrm{O}_{2}$ & 5.70 & 1033 \\
\hline
\end{tabular}

When the input flow boundaries of the stack model are identical to the experimental data, the key output parameters, such as the stack voltage, power output, and average stack temperature, can be compared with the experimental values. The mode switching between SOFCs and SOECs was modeled and validated with the experimental data $(I-V) . I-V$ measurements were performed first in the SOFC mode and then in the SOEC mode. The simulated stack voltage was calculated as eight times of the average SRU voltage, whereas the experimental data used for comparison is the sum of the eight SRU voltages. The current density variation during SOFC-SOEC mode switching is shown in Fig. 2(a). The model output parameters (voltage, power, and temperature) are plotted in Fig. 2(b)-4(d). The deviations in stack voltage and temperature and their relative errors are plotted in Fig. 2(e)-2(f). The experimental data well agrees with the simulated results, indicating the validity of our model. Fig. 2(c) plots the stack power versus time, where the simulation nearly coincides with the experiment. Fig. 2(d) shows the measured and simulated stack temperature curves that have very similar trends and close values. In fuel cell mode, the stack temperature increases monotonically with the current density, as both the fuel cell reaction and ohmic loss release heat. In the electrolysis mode, the electrolysis reaction is endothermic, whereas ohmic loss releases heat. Hence, the 
slope of the stack temperature versus current density (or vs. time as in Fig. 2d) is not that steep, as in SOFC mode. For the stack voltage, a maximum deviation of $0.116 \mathrm{~V}$ or $1.34 \%$ of the measured stack voltage is observed as shown in Fig. 2(e). This results in a deviation of $\sim 2 \mathrm{~W}$ in stack power, which is not easily visible in Fig. 2(c). Fig. 2(f) illustrates the deviation of stack temperature, showing a maximum deviation of $7 \mathrm{~K}$ or $0.65 \%$.

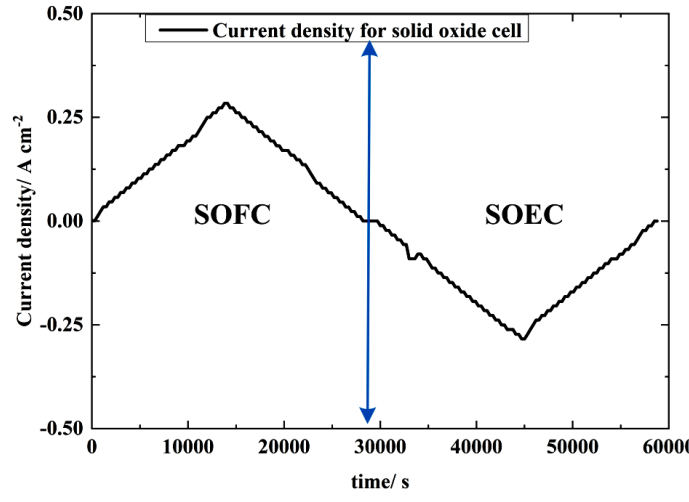

(a) Current density variation trend

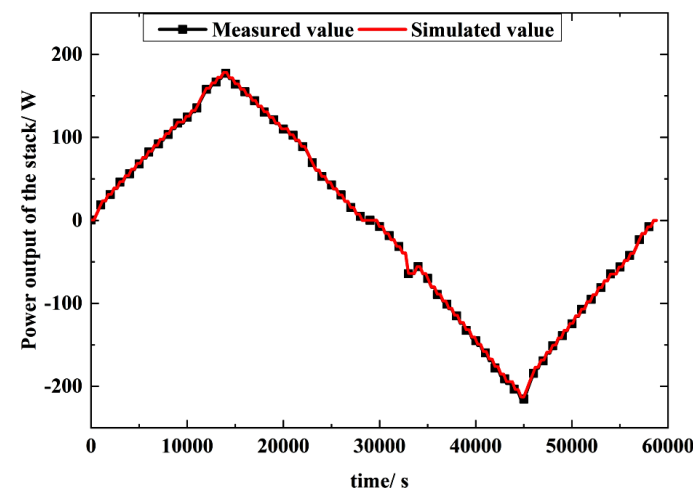

(c) Power output

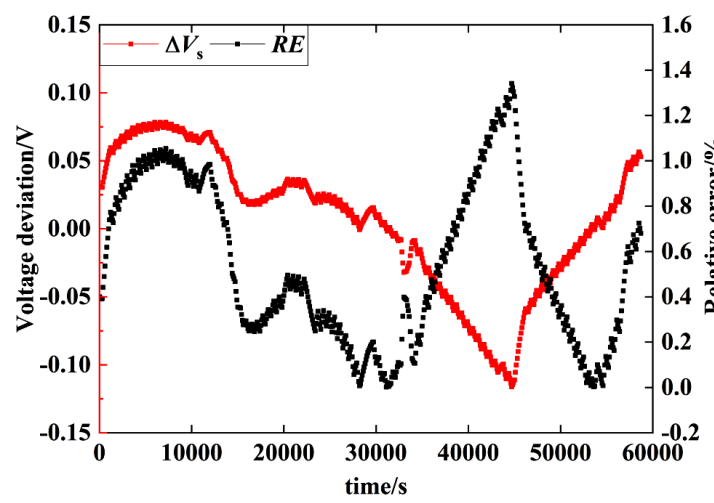

(e) Stack voltage deviation and relative error

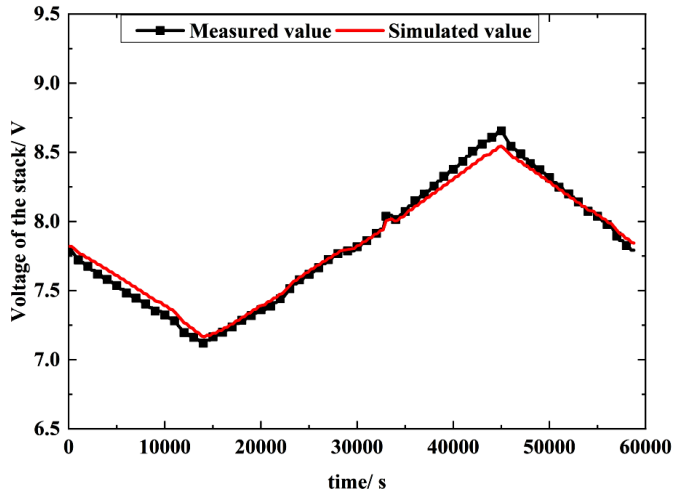

(b) Voltage of the experimental stack

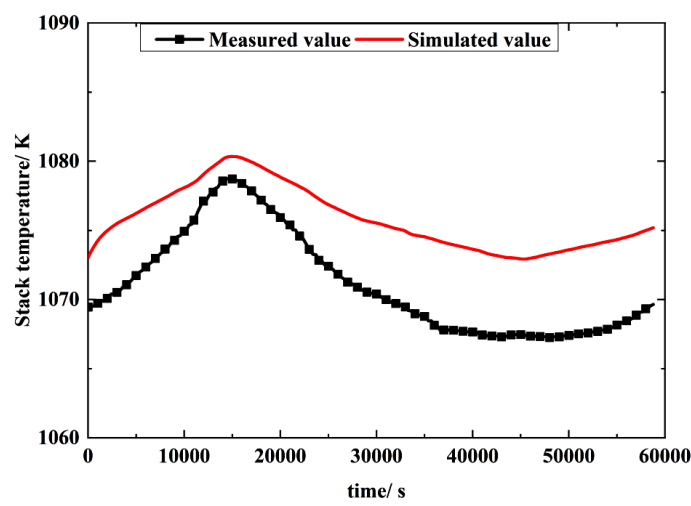

(d) Stack temperature

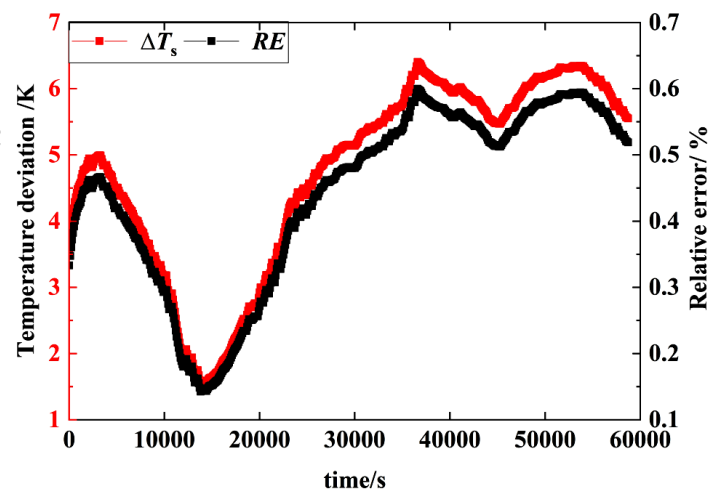

(f) Stack temperature deviation and relative error

Fig. 2 Validation of the dynamic SOC-stack model

\section{Analysis methodology}

\subsection{Fuel utilization rate of the stack during mode switching operation}


When the reversible SOC stack works in SOFC mode, the utilization rate $\left(u_{\mathrm{i}}\right)$ of the gas can be calculated using Eq. (25). The difference between the inlet and outlet flow rates of fuel is utilized by the cell. During the transient process, $u_{\mathrm{i}}$ may be affected by the inlet and outlet fuel flow rates, as well as the current density. The current density of the cell determines the rate of the electrochemical reaction between $\mathrm{H}_{2}$ and $\mathrm{O}^{2-}$. In the SOFC mode, the fuel utilization is positive, whereas in the SOEC mode, it becomes negative, because $\mathrm{H}_{2}$ is produced from the electrochemical reactions. In this paper, only the utilization of hydrogen is considered.

$$
\begin{aligned}
& u_{\mathrm{i}}=\frac{\dot{m}_{\mathrm{in}} \cdot x_{\mathrm{in}, \mathrm{i}}-\dot{m}_{\text {out }} \cdot x_{\mathrm{out}, \mathrm{i}}}{\dot{m}_{\mathrm{in}} \cdot x_{\mathrm{in}, \mathrm{i}}}, \\
& x_{\text {out }, \mathrm{i}}=\frac{M_{\mathrm{i}}}{\sum_{i=1}^{7} M_{\mathrm{i}}},
\end{aligned}
$$

where $x_{\mathrm{in}, \mathrm{i}}$ signifies the fraction of the inlet gas species; and $x_{\mathrm{out}, \mathrm{i}}$ represents the fraction of the outlet gas species.

\subsection{Temperature variation rate of the stack during transient processes}

For the SOC, when the work medium boundaries and the current density vary, the thermal status of the stack will be affected. The load cycling process and mode switching operations have significant influences on thermal fatigue and even the material's degradation. By modifying Eq. (20), the temperature variation rate $\left(\frac{d T_{s}}{d \tau}\right)$ of the stack can be obtained directly. For maintaining the long-time operation in SOC, $\left|\left(\frac{d T_{s}}{d \tau}\right)\right|$ should be kept at a relatively low level. In this study, $1 \mathrm{~K} \mathrm{~min}^{-1}$ was chosen as the criterion for the temperature variation rate of SOC stacks, that is, the upper limit for safe operation $[57,58]$.

$$
\frac{d T_{\mathrm{s}}}{d \tau}=\frac{\dot{m}_{\mathrm{in}, \mathrm{i}} \dot{h}_{\mathrm{in}, \mathrm{i}}-\dot{m}_{\mathrm{out}, \mathrm{i}} \dot{h}_{\mathrm{out}, \mathrm{i}}+\phi \cdot \dot{m}_{\mathrm{chem}, \mathrm{i}} \dot{h}_{\mathrm{out}, \mathrm{i}}-\dot{W}+\frac{j N A_{\mathrm{cell}}}{2 F} \cdot \dot{Q}_{\mathrm{react}}+\dot{Q}_{\mathrm{ext}}+\dot{Q}_{\mathrm{int}}}{C_{\mathrm{s}} M_{\mathrm{s}}},
$$

\subsubsection{Reversible efficiency of the SOC stack during mode switching transient processes}

For the evaluation of the energy conversion and storage performance throughout one charge/discharge cycle in the stack, we introduce in this work a term called reversible efficiency $\left(\eta_{\mathrm{re}}\right) . \eta_{\mathrm{re}}$ is defined as the total electrical energy produced by the stack during fuel cell mode divided by the total electrical energy supplied to the stack in electrolysis mode. As shown in Fig. 3, the SOC works in electrolysis mode for a period of $2 \mathrm{~T}_{0}$, and then switches to fuel cell mode for another $2 \mathrm{~T}_{0}$. E_In represents the energy consumed in storage mode (SOEC), whereas $E_{-}$Out represents the electrical power produced in the production mode (SOFC). The ratio of $E_{-}$Out and $E_{-}$In represents the reversible efficiency in one mode switching cycle. Notably, during model validation (Section 2.3), the cycle was designed as 
SOFC-SOEC in accordance with the experimental $I-V$ data. For the parametric study presented below, the cycle is changed to SOEC-SOFC to accurately mimic the scenario "Power to Gas to Power". Alternately, SOFC-SOEC cycle may also be relevant in some occasions, but this part is omitted in this study for conciseness. In this work, the reversible efficiency is calculated considering the stack only and excluding the balance of the plant (BOP) components. When taking the BOP components into account, the efficiency of a reversible system can be obtained and the values will be lower than those (reversible efficiency, $\eta_{\mathrm{re}}$ ) reported in this work, as the BOP components require additional energy input.

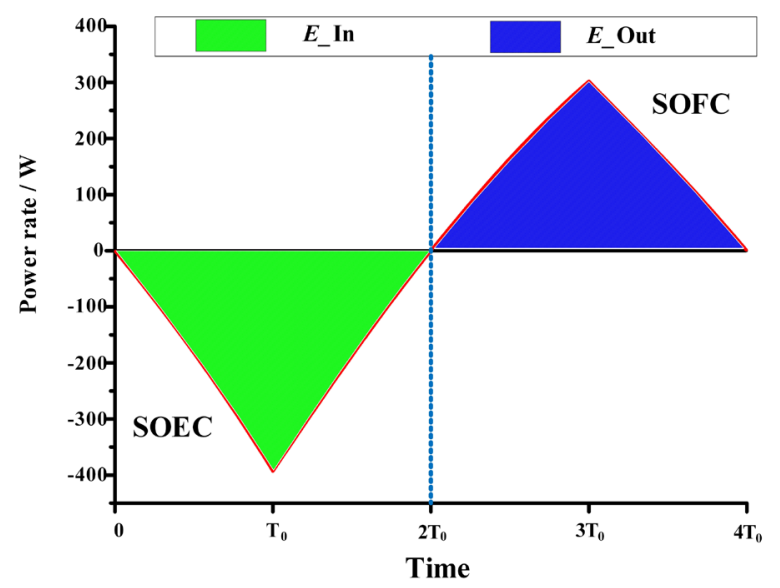

Fig. 3 Mode switching process for an SOC cell stack

$$
\eta_{\mathrm{re}}=\frac{\int_{2 T_{0}}^{4 T_{0}}|\dot{W}| d \tau}{\int_{0}^{2 T_{0}}|\dot{W}| d \tau} \times 100 \%,
$$

where $T_{0}$ is a quarter of the mode switching cycle period.

In an actual SOC plant, the furnace does not exist, and the boundaries of the stack can be regarded as adiabatic to the environment (neglecting the heat loss to the environment). In the SOEC mode, stack temperature decreases due to the endothermic reactions, whereas in the SOFC mode, stack temperature increases, because the power generation process is exothermic. In total, after one cycle in the SOC stack, the temperature of the stack will increase, that is, not all the input electrical power can be converted back, and part of this power is released as heat, where $\eta_{\mathrm{re}}<1$. This condition occurs primarily because the heat released in the SOFC mode and the heat absorbed in the SOEC mode do not cancel each other out. In the adiabatic mode, this condition increases the stack temperature because of the net heat generated. A lower net heat generated means less increase in stack temperature after one mode switching cycle and a closer value of $\eta_{\text {re }}$ to 1 . 


\section{Results and discussion}

The stack may operate in off-design work conditions due to the electricity demand. A typical switching cycle for the reversible SOC stack is illustrated in Fig. 4. The entire cycle of switching operation between SOEC and SOFC is $40000 \mathrm{~s}\left(\mathrm{~T}_{0}=10000 \mathrm{~s}\right)$. In the first half cycle (A-B-C), the stack works in the SOEC mode (the current is negative), whereas in the second half cycle (C-D-E), the stack works in the SOFC mode (the current is positive). The amplitude of the current density ( $\left.I_{\text {peak }}\right)$ is $0.25 \mathrm{~A} \mathrm{~cm}^{-2}$, and the current variation format is a triangular wave. The triangular wave, including the ramp format, is the same as that in the experimental stack testing. The ramping rate is determined by the peak current density $\left(0.25 \mathrm{~A} \mathrm{~cm}^{-2}\right)$ and the cycle time (40 $\left.000 \mathrm{~s}\right)$. Mode switching occurs in a step manner, in which the stack has to switch first from SOEC operation to open current voltage (OCV), and then from OCV to SOFC operation, or vice versa. Theoretically, if the same gas feeds are used for both SOFC and SOEC operations, then the switching from SOEC to OCV and further to SOFC may occur in seconds. However, for minimizing the thermal shock, an appropriate ramping rate choice for current density might be needed.

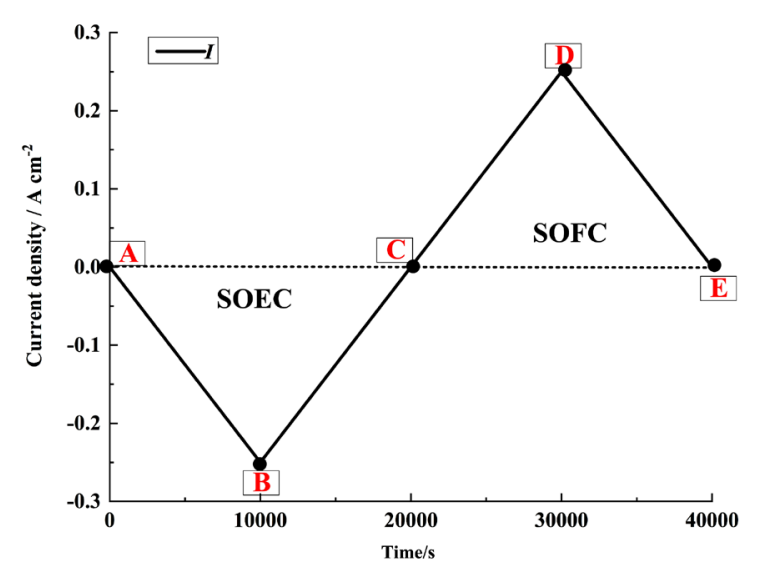

Fig. 4 Current density of the stack in a switching cycle

The transient performance of the stack depends strongly on the stack designing and operating parameters. A parametric variation study is necessary to explore general trends. The basic stack design parameters and the boundary conditions are listed in Tables 3 and 4. Different from the model validation part, the inlet temperature of the work medium was $1073 \mathrm{~K}$. The following parts present the influences of the inlet boundaries (operational parameters including fuel fraction, inlet gas temperature, operation pressure, current density, and mode switching frequency) and the thermal capacity (design parameter) of the stack throughout the mode switching transient processes. The temperature $\left(T_{\mathrm{s}}\right)$, temperature variation rate $\left(\frac{d T_{\mathrm{s}}}{d \tau}\right)$, voltage $\left(V_{\mathrm{s}}\right)$, output power $(\dot{W})$, fuel utilization $\left(u_{\mathrm{H}_{2}}\right)$, and 
reversible efficiency $\left(\eta_{\mathrm{re}}\right)$ of the stack were illustrated and analyzed in detail.

In the actual experimental stack testing [55], the stack was placed inside a thermostatical furnace. As shown in Section 2, during mode switching process, the stack temperature varied up to $10 \mathrm{~K}$. When the stack is placed in an adiabatic environment (as presented in the simulation below), $T_{\mathrm{s}}$ may greatly vary during transient operations.

\subsection{Fuel fraction $\left(x_{\mathrm{H}_{2}}\right)$}

The components of the fuel electrode inlet work medium are hydrogen $\left(\mathrm{H}_{2}\right)$ and steam $\left(\mathrm{H}_{2} \mathrm{O}\right)$, and oxygen is the only gas species fed to the oxygen electrode. For the fuel electrode, the molar ratio of $\mathrm{H}_{2}$ to $\mathrm{H}_{2} \mathrm{O}$ is $50: 50\left(x_{\mathrm{H}_{2}}=0.5\right)$ for the basic work condition. To study the influence of fuel gas composition on the stack transient behavior, an extensive parameter study on $x_{\mathrm{H}_{2}}$ from 0.2 to $0.6\left(x_{\mathrm{H}_{2} \mathrm{O}}\right.$ varies from 0.8 to 0.4 accordingly $)$ was carried out and the results are presented in this section.

The initial values for $T_{\mathrm{s}}$ and $I$ at the beginning of the cycle are $1073 \mathrm{~K}$ and $0 \mathrm{~A} \mathrm{~cm}^{-2}$, respectively. As the input parameter, the variation profile of $I$ is illustrated in Fig. 4. The stack undergoes an entire cycle, beginning from SOEC and ending in SOFC with current density following a triangle wave curve. For the model output parameters, the variations in $T_{\mathrm{s}},\left(\frac{d T_{\mathrm{s}}}{d \tau}\right), V_{\mathrm{s}}, \dot{W}, u_{\mathrm{H}_{2}}$, and $\eta_{\mathrm{re}}$ during the mode switching processes are presented in Figs. 5(a)-5(f). At $x_{\mathrm{H}_{2}}=0.2, T_{\mathrm{s}}$ first decreases from $1073 \mathrm{~K}$ to $1046 \mathrm{~K}$ and then increases and reaches a maximum of $1086 \mathrm{~K}$ at the end of the cycle. The maximum stack-temperature variation $\left(\Delta T_{\mathrm{s}}\right)$ is approximately $40 \mathrm{~K}$. The profile of $\left(\frac{d T_{\mathrm{s}}}{d \tau}\right)$ is similar to that of $I$. Due to the electrochemical reaction, the sign of $\left(\frac{d T_{s}}{d \tau}\right)$ is determined by the current direction. When $I$ is negative, the stack works in SOEC mode, and the electrochemical reaction is endothermic, and vice versa. $\left(\frac{d T_{s}}{d \tau}\right)$ decreases from 0 to $-0.17 \mathrm{~K} \mathrm{~min}^{-1}$ at the peak current density in the SOEC mode, and then increases to $0.25 \mathrm{~K} \mathrm{~min}^{-}$ ${ }^{1}$ at the peak current density in SOFC mode, and eventually returns to 0 . The maximum $\left|\frac{d T_{s}}{d \tau}\right|$ is $0.25 \mathrm{~K} \mathrm{~min}^{-1}$, which is below the suggested safe operation criterion of $1.0 \mathrm{~K} \mathrm{~min}^{-1}[58]$, which is indicated by the two red dashed lines in Fig. 5(b). By changing the electrolysis current density from 0 to $-0.25 \mathrm{~A} \mathrm{~cm}^{-2}$, the stack voltage $V_{\mathrm{s}}$ increases from $7.3 \mathrm{~V}$ to $7.9 \mathrm{~V}$. In the SOFC mode, with current density increasing from 0 to $0.25 \mathrm{~A} \mathrm{~cm}^{-2}, V_{\mathrm{s}}$ decreases from $7.6 \mathrm{~V}$ to $6.5 \mathrm{~V}$. The stack voltage $V_{\mathrm{s}}$ values at $0,2 \mathrm{~T}_{0}$, and $4 \mathrm{~T}_{0}$ are $7.3,7.4$, and $7.2 \mathrm{~V}$, respectively. The difference is caused by the difference in stack temperatures, even though the current density is $0 \mathrm{~A} \mathrm{~cm}^{-2}$ in all the three cases. $\dot{W}$ is the product of $I, A_{\text {cell, }}$, and $V_{\mathrm{s}}$, and the profile of $\dot{W}$ is very similar to that of $I$. According to Eq. (25), $u_{\mathrm{H}_{2}}$ is negative in the SOEC mode and positive in the SOFC mode for steady-state work status, and its evolution over time adopts a 
triangle waveform when the stored work medium in the stack is neglected. The smoothness of the $u_{\mathrm{H}_{2}}$ curves indicates its delayed characteristics during transient processes. $\eta_{\mathrm{re}}$ is an index of reversible energy-conversion efficiency for an integrated charging and discharging process with a value of $87.01 \%$ at $x_{\mathrm{H}_{2}}=0.2$.

With increasing $x_{\mathrm{H}_{2}}$ from 0.2 to 0.6 , the maximum stack temperature variation $\Delta T_{\mathrm{s}}$ decreases from $40 \mathrm{~K}$ to 30 $\mathrm{K}$. The decrease in $\Delta T_{\mathrm{s}}$ indicates the decrease in thermal fatigue during mode switching transient processes. This condition is further reflected by the $25 \%$ decrease in the maximum value of $\left|\frac{d T_{s}}{d \tau}\right|$. The curves of $V_{\mathrm{s}}$ for different $x_{\mathrm{H}_{2}}$ values are nearly parallel. According to Eqs. (1) and (2), $V_{\mathrm{s}}$ depends on the partial pressure of $\mathrm{H}_{2}, \mathrm{O}_{2}$, and $\mathrm{H}_{2} \mathrm{O}$. When $I$ is identical, $V_{\mathrm{s}}$ increases with the increasing in $x_{\mathrm{H}_{2}}$. The maximum value of $\Delta V_{\mathrm{s}}$ during one cycle is $0.6 \mathrm{~V}$ at $x_{\mathrm{H}_{2}}=$ 0.2 , and this difference is more obvious with increasing $x_{\mathrm{H}_{2}}$. An enlarged part of the $\dot{W}$ curves at the peak current densities are presented in Figs. 5(g) and 5(h). With increasing $x_{\mathrm{H}_{2}}$ from 0.2 to 0.6 , the peak power consumption in SOEC mode increases from $175.4 \mathrm{~W}$ to $189.2 \mathrm{~W}$, whereas the peak power production in SOFC increases from 143.7 $\mathrm{W}$ to $162.4 \mathrm{~W}$. Considering that $u_{\mathrm{H}_{2}}$ has a direct relation with $x_{\mathrm{H}_{2}}$, the difference in $u_{\mathrm{H}_{2}}$ is obvious. Under different $x_{\mathrm{H}_{2}}$ values, the maximum difference in $u_{\mathrm{H}_{2}}$ is 0.50 when $I$ reaches its peak value. Theoretically, $u_{\mathrm{H}_{2}}$ depends on current density, inlet hydrogen molar fraction, and gas flow. At the same current density, $u_{\mathrm{H}_{2}}$ decreases with increasing $x_{\mathrm{H}_{2}}$. With $x_{\mathrm{H}_{2}}$ varying from 0.2 to $0.5, \eta_{\mathrm{re}}$ increases from $87.01 \%$ to $89.92 \%$. The maximum value of $\eta_{\text {re }}$ is $89.92 \%$ at $x_{\mathrm{H}_{2}}=0.5$. Further increase in $x_{\mathrm{H}_{2}}$ from 0.5 to 0.6 results in decreasing $\eta_{\text {re }}$ by $0.01 \%$. In conclusion, an inlet hydrogen fraction of $0.5-0.6$ leads to the smallest stack-temperature variation and the highest reversible efficiency during the SOEC-SOFC reversible operation. When the ratio of $\mathrm{H}_{2}$ and $\mathrm{H}_{2} \mathrm{O}$ is $50: 50$, the diffusion voltage loss is the least compared with other work conditions. This may be one of the reasons that the $\eta_{\mathrm{re}}$ reaches the maximum when $x_{\mathrm{H}_{2}}=0.5$. 


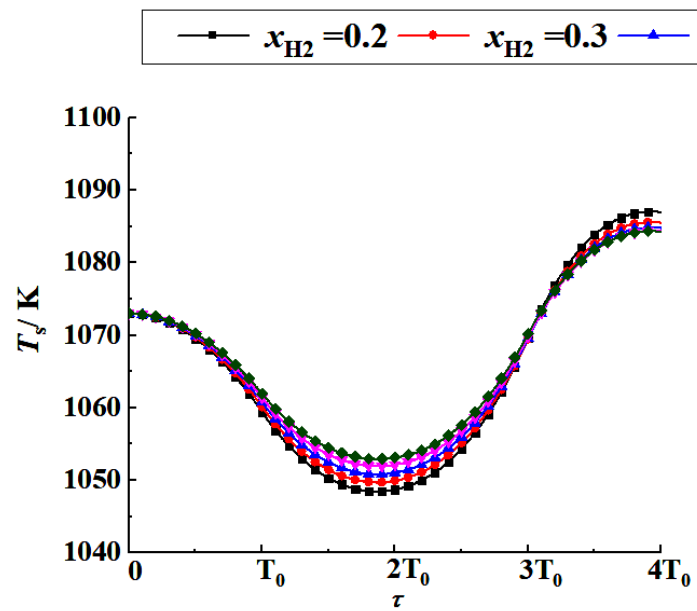

(a)

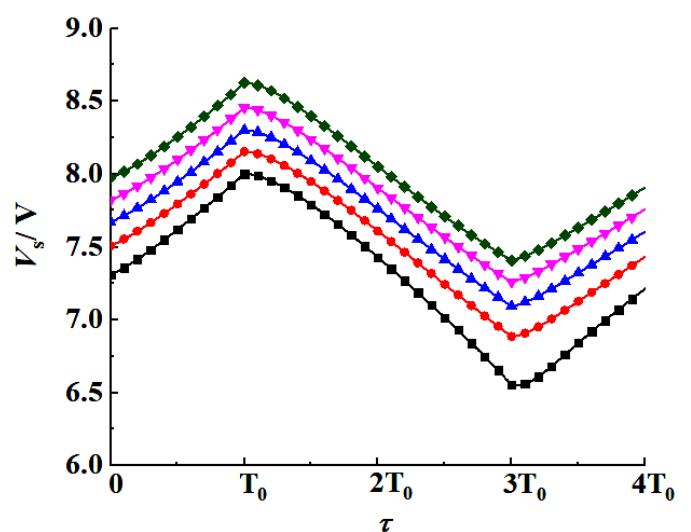

(c)

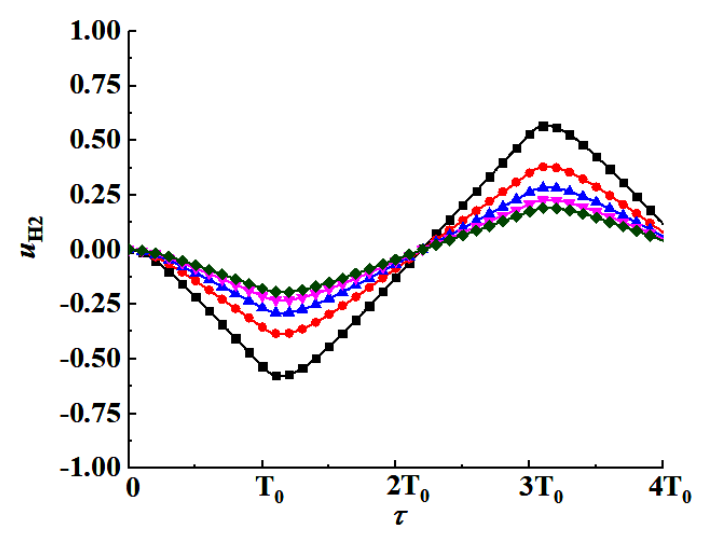

(e)

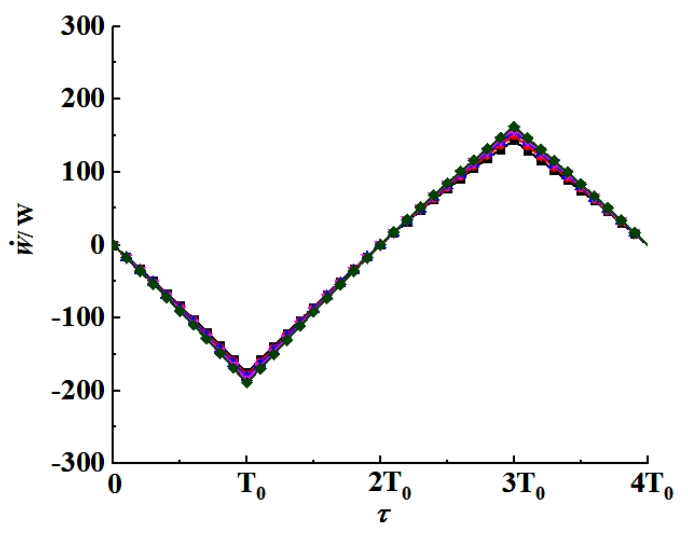

(d)

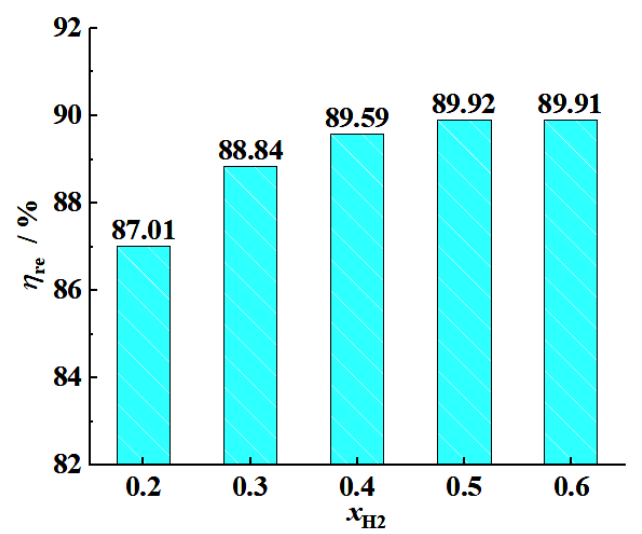

(f) 


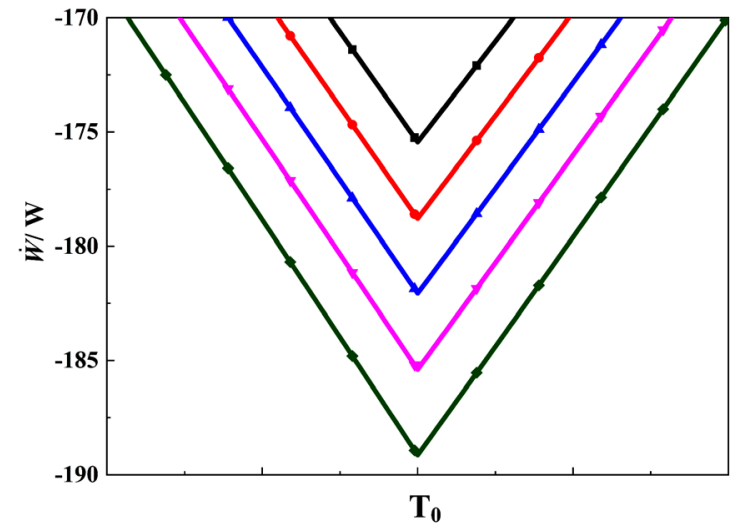

(g)

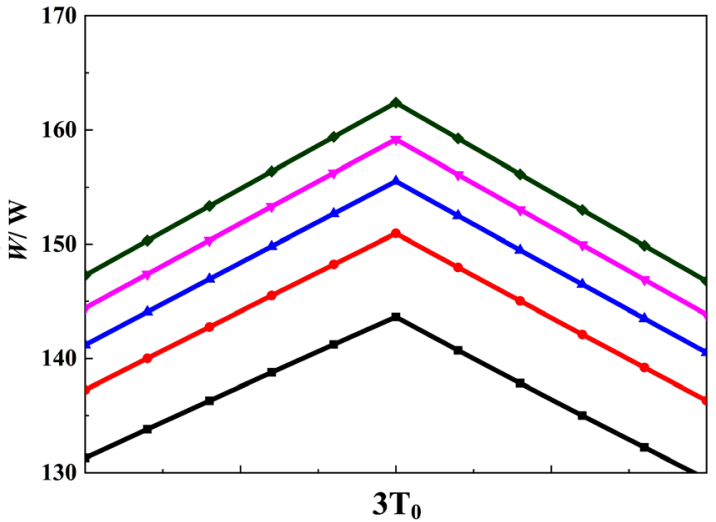

(h)

Fig. 5 (a) Temperature, (b) temperature variation rate, (c) voltage, (d) power, (e) fuel utilization, (f) reversible efficiency, and (g), (h) enlarged view of $\dot{W}$ of the stack with different $x_{\mathrm{H}_{2}}$

\subsection{Work medium inlet temperature $\left(T_{\text {in }}\right)$}

The inlet temperature of the work medium ( $T_{\text {in }}$ in Kelvin) affects the thermal status of the stack and the electrochemical reactions. The designed inlet gas temperature is $1073 \mathrm{~K}$ in rated work conditions. To explore the allowance and the most suitable $T_{\text {in, }}$, four values are selected: $973,1073,1173$, and $1273 \mathrm{~K}$. The $T_{\mathrm{s}}$ curves under different $T_{\text {in }}$ are approximately parallel. For an elaborate description on $T_{\mathrm{s}}$, the curve of $\left(\frac{d T_{\mathrm{s}}}{d \tau}\right)$ can reflect the detailed variation during transient processes. The trends of variation in $\left(\frac{d T_{\mathrm{s}}}{d \tau}\right)$ for different $T_{\text {in }}$ values are similar, and closely follow the variations in $I$. As shown in Fig. $6(\mathrm{~b})$, the highest $\left|\frac{d T_{\mathrm{s}}}{d \tau}\right|$ is $0.30 \mathrm{~K} \mathrm{~min}^{-1}$, which appears at $3 \mathrm{~T}_{0}$ with $T_{\text {in }}=$ $973 \mathrm{~K}$. At identical $I$, with increasing $T_{\mathrm{in}}, V_{\mathrm{s}}$ increases in the SOFC mode but deceases in the SOEC mode. The change in SOEC mode is much higher than that in the SOFC mode. The maximum $\left|\Delta V_{s}\right|$ in one mode switching cycle is 3 V with $T_{\text {in }}=973 \mathrm{~K}$. Increasing $T_{\text {in }}$ reduces the stack voltage variation, especially in the SOEC mode. Fig. 8(d) presents the variation of $\dot{W}$ with time under different $T_{\text {in }}$ values. The enlarged views at minimum and maximum $\dot{W}$ are presented in Figs. 6(g) and 6(h). The power consumption in the SOEC mode decreases with increasing $T_{\text {in, }}$ whereas the power production in SOFC mode increases with increasing $T_{\text {in. }}$. The difference in $u_{\mathrm{H}_{2}}$ is minor. The thermal status of the stack affects the stored work medium's thermal states, such as specific volume. Even at the same current density, $u_{\mathrm{H}_{2}}$ differs due to the different amounts of $\mathrm{H}_{2}$ involved in the electrochemical reactions. The minor difference in $u_{\mathrm{H}_{2}}$ may be due to the molar quantity of the stored work medium that is inversely proportional to $T_{\mathrm{s}}$. When $T_{\text {in }}$ varies from 973 to $1273 \mathrm{~K}, \eta_{\mathrm{re}}$ increases from $80.49 \%$ to $93.62 \%$, indicating that $T_{\mathrm{s}}$ and $T_{\text {in }}$ have great influence on the reversible efficiency of the SOC. Ohmic voltage loss dominates all the voltage losses in SOC cells. 
A high operating temperature reduces the electrolyte resistance. According to Equations (8)-(10), with increasing in the cell temperature $\left(T_{\mathrm{c}}\right), \sigma_{\mathrm{el}}$ increases and $V_{\mathrm{ohm}}$ decreases. In total, when increasing the stack operation temperature (such as rising the gas inlet temperature), the ohmic loss will be reduced both in SOEC and SOFC modes. $\eta_{\mathrm{re}}$ increases accordingly as shown in Fig. 6(f). In reality the choice of operating temperature is limited by several factors, among which the performance and durability of cells, stack components, and stacks are the most important ones. For example, the widely used ferritic stainless-steel interconnects are limited to an operation temperature of $1123 \mathrm{~K}$ or lower. At the system level, we should also consider the BOP components and the overall system efficiency.

$$
\longrightarrow T_{\text {in }}=973 \multimap T_{\text {in }}=1073 \multimap T_{\text {in }}=1173 \multimap T_{\text {in }}=1273
$$

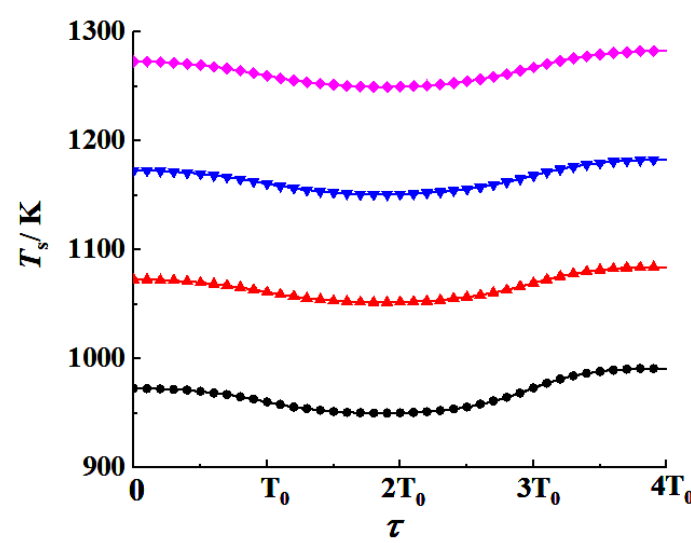

(a)

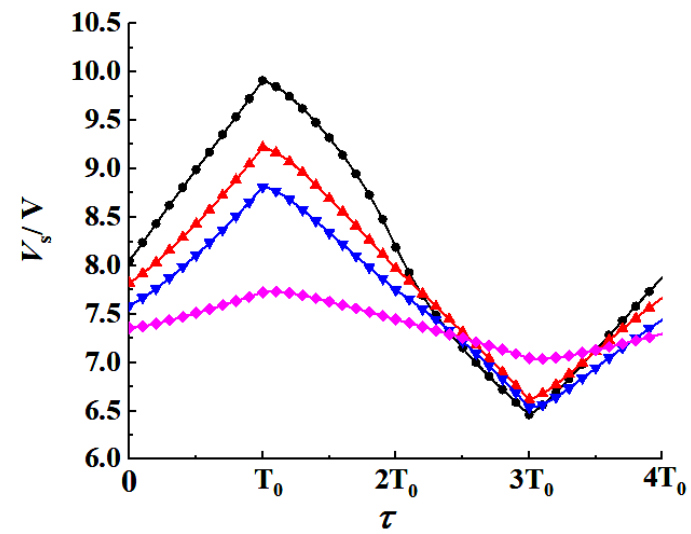

(c)

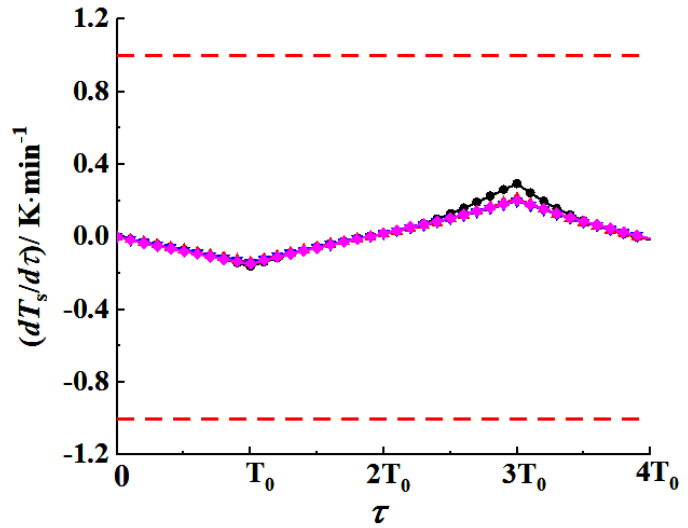

(b)

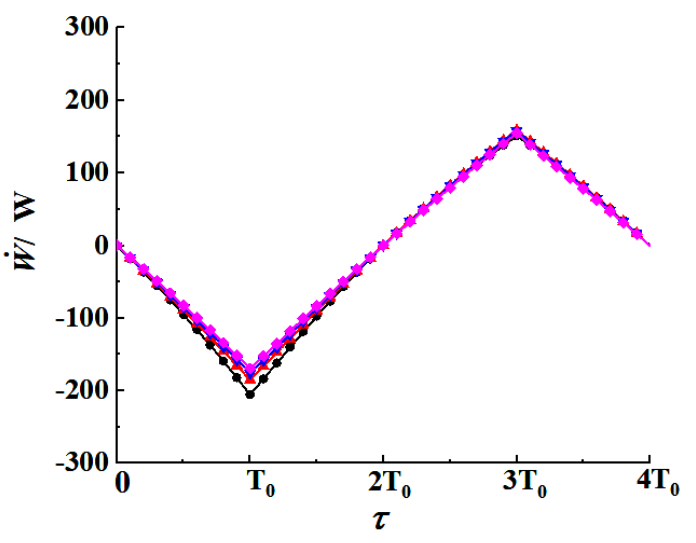

(d) 


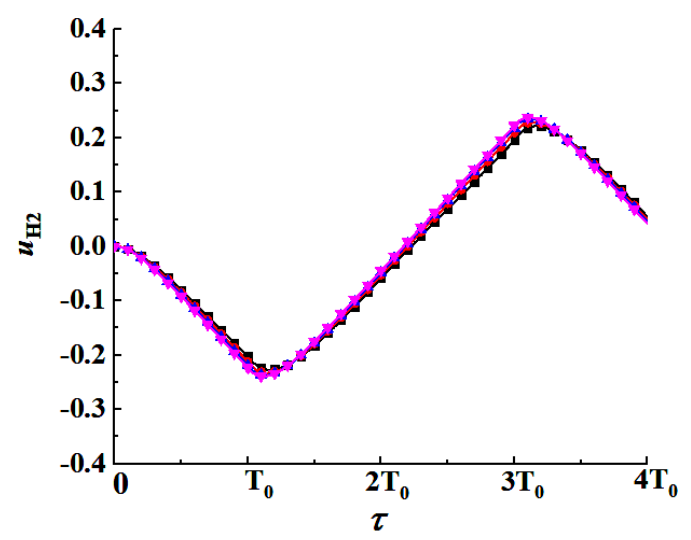

(e)

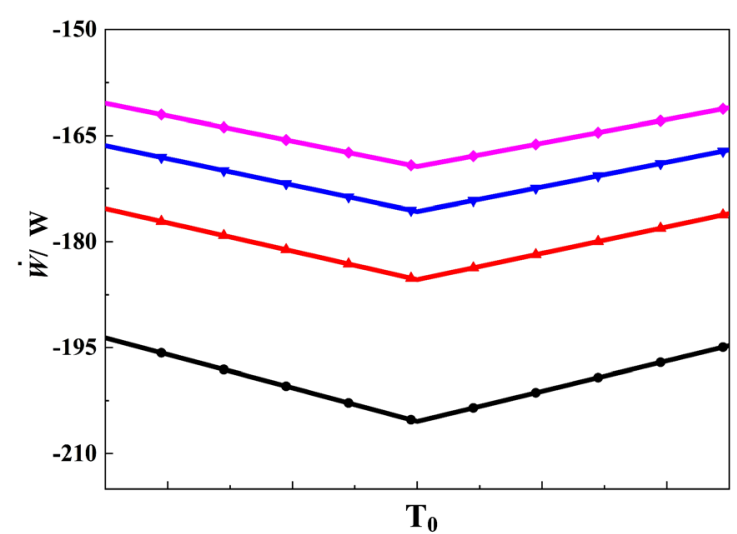

(g)

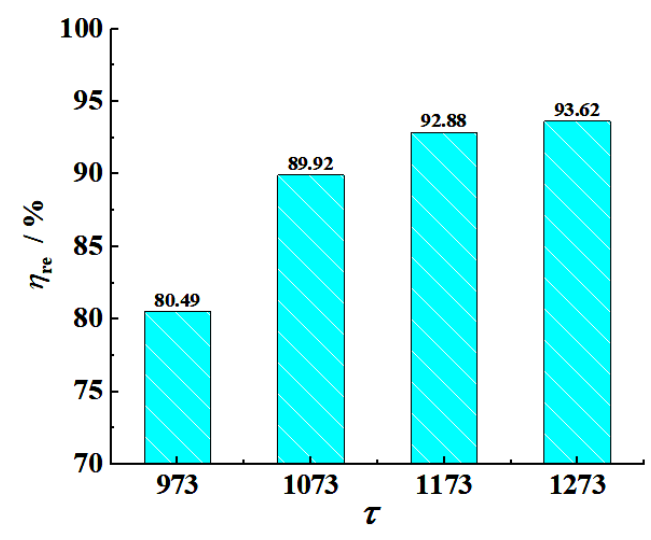

(f)

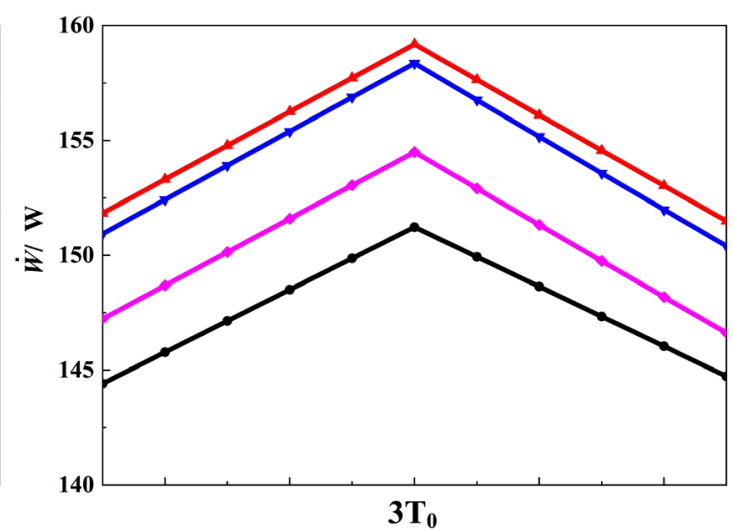

(h)

Fig. 6 (a) Temperature, (b) temperature variation rate, (c) voltage, (d) power, (e) fuel utilization, (f) reversible efficiency, and (g), (h) enlarged view of $\dot{W}$ of the stack with different $T_{\text {in }}$

\subsection{Work medium operation pressure $(p)$}

The pressure of the work medium $(p)$ may affect the electrochemical reactions operating in the stack. The operational pressure is set to $0.1 \mathrm{MPa}$. A parametric study of the operational pressure on stack transient behavior was conducted, and the results are presented in this section. A dimensionless parameter of the stack operational pressure $\left(R_{p}\right)$ was proposed to represent the variation in operational pressure.

$$
R_{p}=\frac{p}{p_{0}}
$$

where $p_{0}$ is the designed operational pressure of the stack $(0.1 \mathrm{MPa})$.

The transient behavior of the stack with different $R_{p}$ is illustrated in Fig. 7. With increasing $R_{p}$, the stack temperature $T_{\mathrm{s}}$ increases slightly in SOEC mode but decreases in SOFC mode. Hence, the stack temperature variation $\left(\Delta T_{\mathrm{s}}\right)$ reduces. This finding is also observed for $\left|\frac{d T_{\mathrm{s}}}{d \tau}\right|$, as shown in Fig. 7(b). The peak stack voltage in the SOEC mode $V_{\mathrm{s}}$ increases from $8.4 \mathrm{~V}$ to $8.7 \mathrm{~V}$ with increasing $R_{p}$ from 1.0 to 4.0 . Although increasing $R_{p}$ can improve $V_{\mathrm{s}}$, the 
improvement in $V_{\mathrm{s}}$ is limited or not distinct, as depicted in Fig. 7(c). According to the governing equation of Eq. (2), by neglecting the influence of $T_{\mathrm{s}}$, increasing $p_{\mathrm{O}_{2}}$ can increases $E$, but the improvement is proportional to $\frac{1}{p_{\mathrm{O}_{2}}}$. The curves of $\dot{W}$ with different $R_{p}$ are nearly in parallel, as shown in Fig. 7(d). The differences at the peak $\dot{W}$ are $5 \mathrm{~W}$ in the SOEC mode and $10 \mathrm{~W}$ in the SOFC mode, as shown in Figs. $7(\mathrm{~g})$ and $7(\mathrm{~h}) . u_{\mathrm{H}_{2}}$ is a function of current density alone at fixed amount of gas reactants. However, during the transient process, with increasing $R_{p}$, the stored work medium increases, thus decreasing fuel utilization at the same current density and enhancing the delayed characteristics in $u_{\mathrm{H}_{2}}$. By increasing $R_{p}$ from 1.0 to 4.0 , the peak $u_{\mathrm{H}_{2}}$ reduces by one third both in the SOEC and SOFC modes. In some operation scenarios, $u_{\mathrm{H}_{2}}$ is set as constant. When the current density varies, the inlet flowrate of the gases to the hydrogen electrode needs to be adjusted beforehand to overcome the time lag effects, as shown in Fig. 9e. At fixed gas flowrate, the current density shall be adjusted in advance to maintain $u_{\mathrm{H}_{2}}$ in an acceptable range. With increasing $R_{p}$ from 1.0 to $4.0, \eta_{\text {re }}$ increases from $89.92 \%$ to $91.72 \%$ monotonically. When increasing the operation pressure, $V_{\mathrm{s}}$ is improved both in SOEC and SOFC modes. The decreasing in stack-temperature fluctuation results in less electricity energy that is converted to thermal energy form in one mode switching cycle. In summary, increasing the stack operation pressure reduces stack-temperature variation and hence increases the reversible efficiency of the SOC stacks. However, from a system point of view, increasing pressure may not necessarily increase the system efficiency, because operating at elevated pressure requires additional energy input.

$$
\longrightarrow R_{p}=1.0 \multimap R_{p}=2.0 \multimap R_{p}=3.0 \multimap R_{p}=4.0
$$

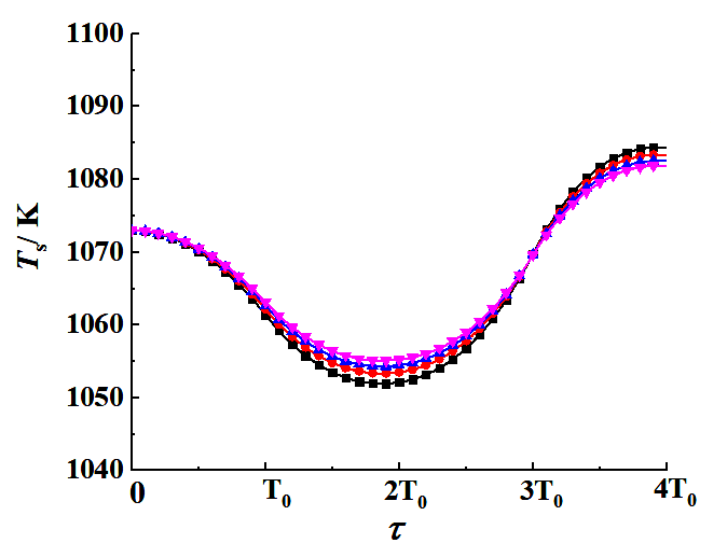

(a)

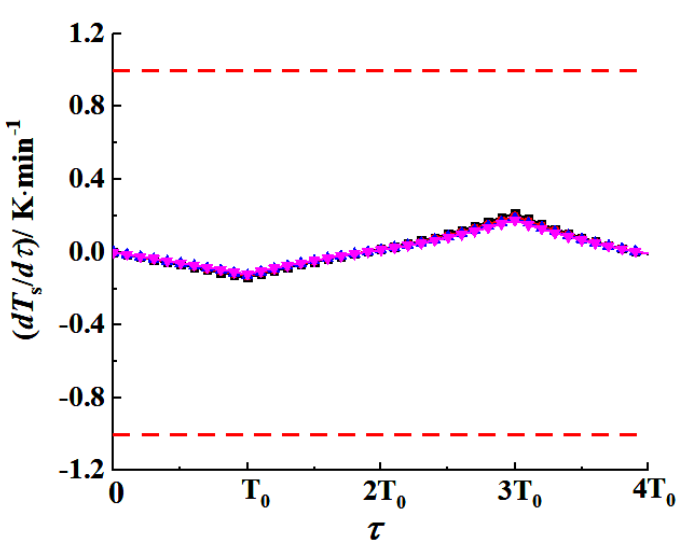

(b) 


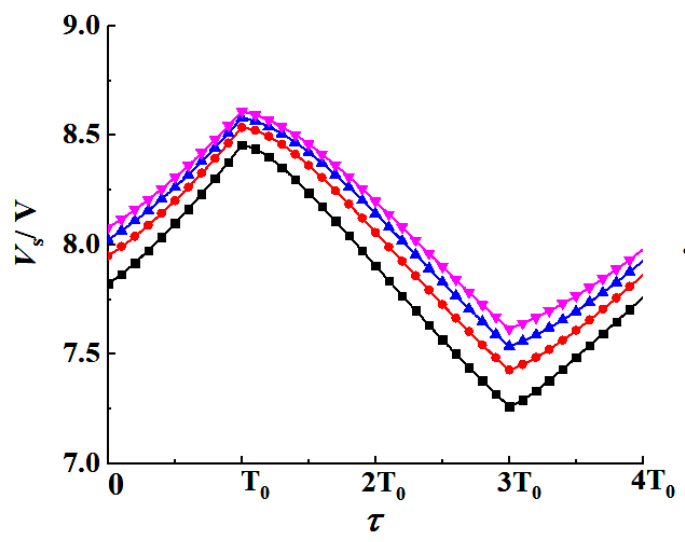

(c)

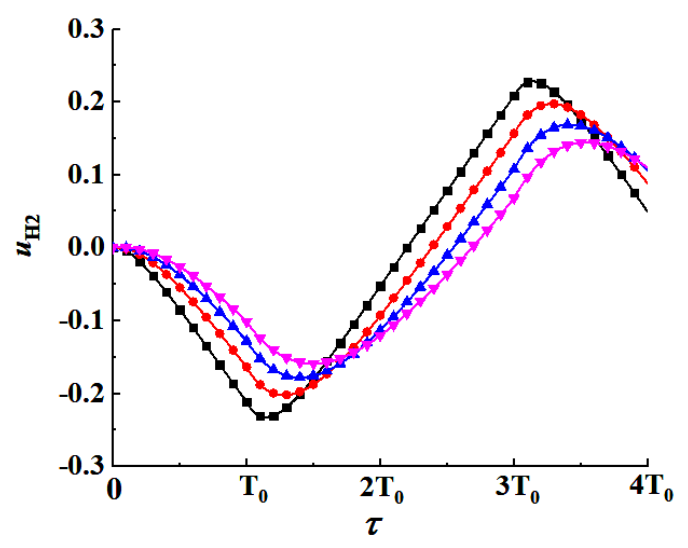

(e)

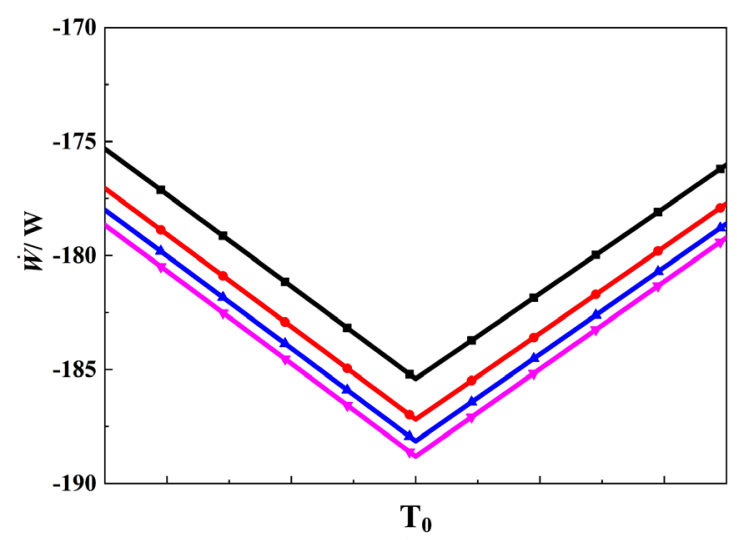

(g)

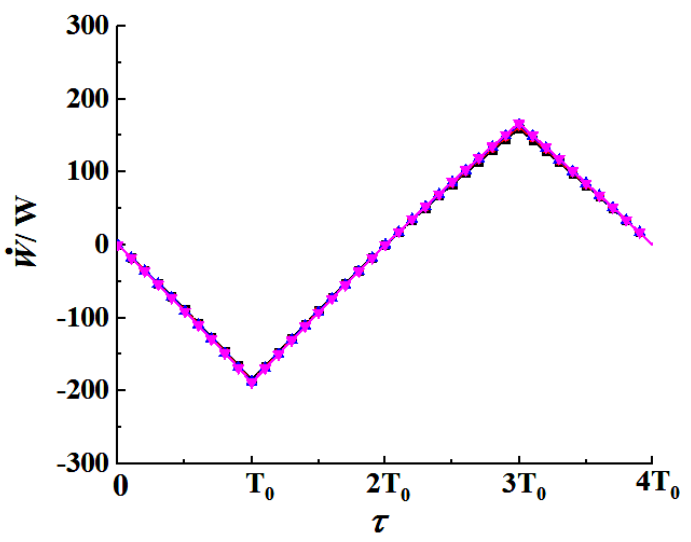

(d)

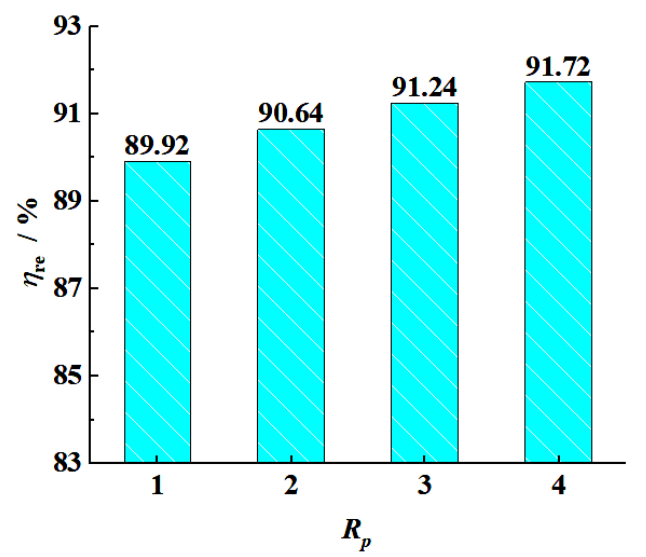

(f)

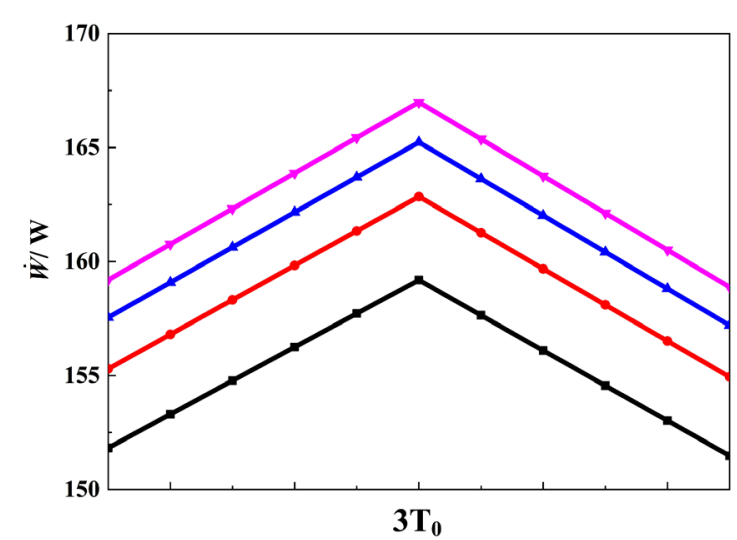

(h)

Fig. 7 (a) Temperature, (b) temperature variation rate, (c) voltage, (d) power, (e) fuel utilization, (f) reversible efficiency, and (g), (h) enlarged view of $\dot{W}$ of the stack with different $R_{p}$

\subsection{Current density amplitude $\left(I_{\text {peak }}\right)$}

For a mode switching process, the allowable current density peak value $\left(I_{\text {peak }}\right)$ represents the capacity of the 
stack power. The starting value of $I_{\text {peak }}$ was set to $0.25 \mathrm{~A} \mathrm{~cm}^{-2}$. A parametric study of $I_{\text {peak }}$ was conducted, and the results are presented in this section. A dimensionless parameter of the operational current density $\left(R_{\mathrm{I}}\right)$ was proposed as follows:

$$
R_{I}=\frac{I_{\text {peak }}}{I_{\text {peak }, 0}},
$$

where $I_{\text {peak }, 0}$ is the value adopted in the experimental stack testing $\left(0.25 \mathrm{~A} \mathrm{~cm}^{-2}\right)$.

The influence of $R_{\mathrm{I}}$ on the stack transient performance is illustrated in Fig. 8. With increasing $R_{\mathrm{I}}$ from 0.5 to 3.0, $\Delta T_{\mathrm{s}}$ proportionally increases from $35 \mathrm{~K}$ to $140 \mathrm{~K}$. As shown in Fig. 8(b), $\left|\frac{d T_{\mathrm{s}}}{d \tau}\right|$ increases in proportion to $I$. The increase in $\left|\frac{d T_{\mathrm{s}}}{d \tau}\right|$ is more pronounced in the SOFC mode than in SOEC mode. At $R_{\mathrm{I}}=3.0$ and at the peak SOFC current density, $\left|\frac{d T_{\mathrm{s}}}{d \tau}\right|$ reaches the maximum value of $1.02 \mathrm{~K} \mathrm{~min}^{-1}$, exceeding the upper limit of allowable stacktemperature variation. Our results indicate that for an adiabatic reversible SOC stack, the maximum allowable current density should not exceed $0.75 \mathrm{~A} \mathrm{~cm}^{-2}$ for the type of stack that we investigated here. For the identical $I, V_{\mathrm{ohm}}$ increases with increasing $R_{\mathrm{I}}$ proportionally. The increase in $R_{\mathrm{I}}$ causes changes in the molar fraction of the reactants accordingly, and Nernst voltage $(E)$ may be affected directly. Considering the SOFC mode, when $R_{\mathrm{I}}$ increases from 1.0 to 2.0, $V_{\text {ohm }}$ will be doubled and $E$ will decrease, as the partial pressure of $\mathrm{H}_{2}$ decreases and that of $\mathrm{H}_{2} \mathrm{O}$ increases. Hence, $V_{\mathrm{s}}$ decreases with increasing $R_{\mathrm{I}}$ as illustrated in Fig. 8(c). The variation of $\dot{W}$ is proportional to the change in $R_{\mathrm{I}}$. This condition is similar to that of $u_{\mathrm{H}_{2}}$, as shown in Fig. 8(e). $I$ reaches its peak value at $3 \mathrm{~T}_{0}$. However, the maximum value of $u_{\mathrm{H}_{2}}$ appears at the time later than $3 \mathrm{~T}_{0}$. The peak value of $u_{\mathrm{H}_{2}}$ appears at the same time for different $R_{\mathrm{I}}$, demonstrating that the delay characteristics is affected by the stack volume and slightly affected $R_{\mathrm{I}}$. With increasing operational current density of the stack, the activation and ohmic voltage losses enhance accordingly. More power is needed in the SOEC mode, and less electricity can be generated in the SOFC mode. Hence, the reversible efficiency $\eta_{\mathrm{re}}$ decreases with increasing $R_{\mathrm{I}}$. In summary, with increasing the peak current density, the fatigue of the stack due to thermal cycling increases, and the reversibility of the energy-conversion process decreases. For the stack to be protected and for maintaining a high $\eta_{\mathrm{re}}$ during the transient operation in an adiabatic environment, the current density needs to be kept within a reasonable range. 


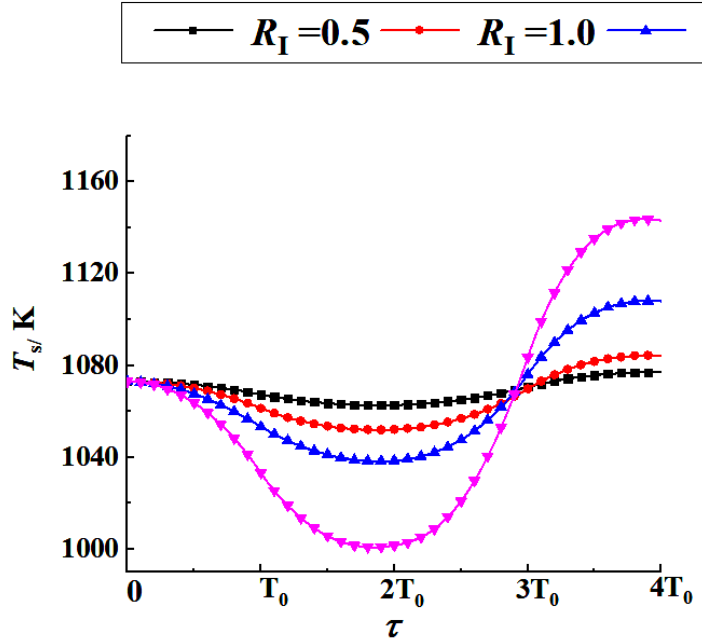

(a)

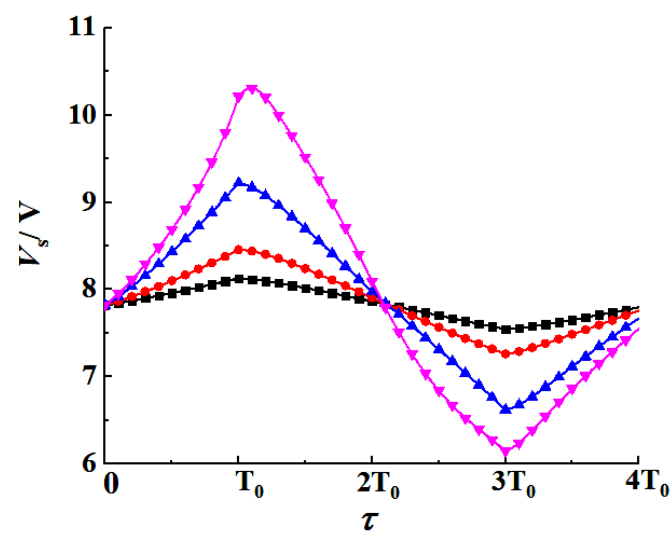

(c)

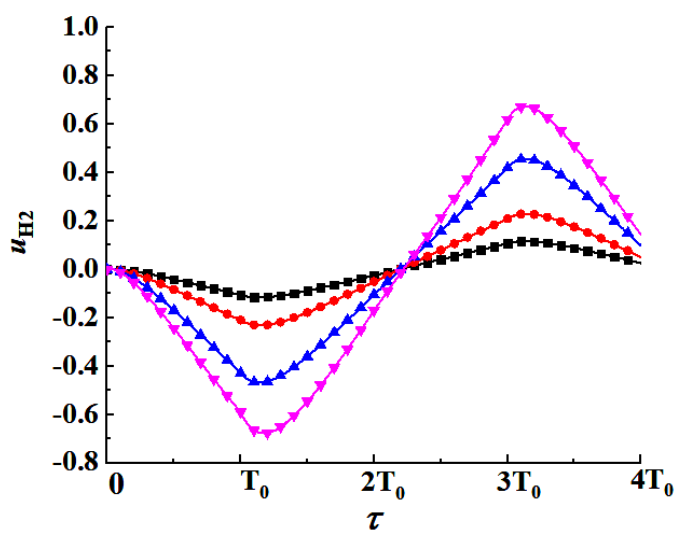

(e)

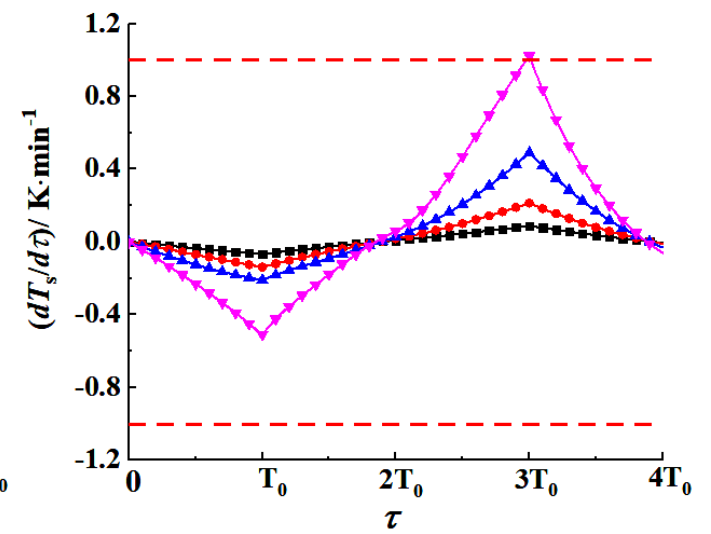

(b)

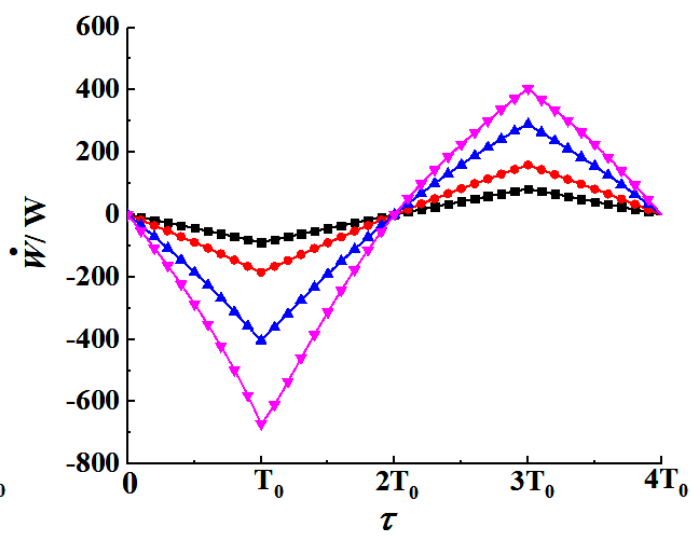

(d)

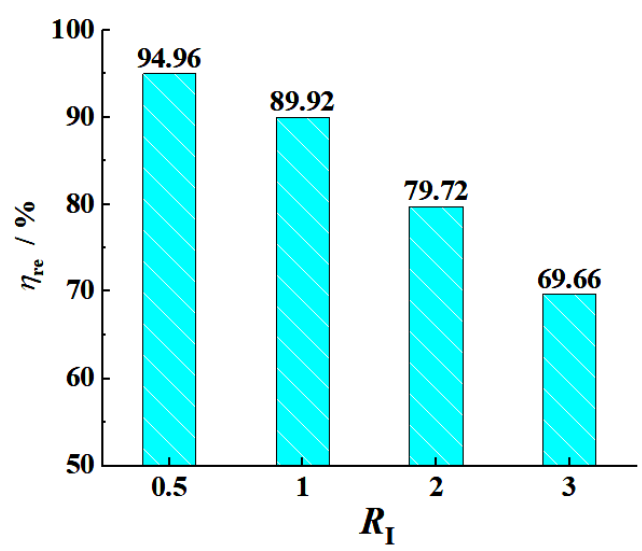

(f)

Fig. 8 (a) Temperature, (b) temperature variation rate, (c) voltage, (d) power, (e) fuel utilization, and (f) reversible efficiency of the stack with different $R_{\mathrm{I}}$ 


\subsection{Mode switching frequency $(f)$}

The operation mode of the stack is determined by the electricity demand. In an actual operational SOC plant, the frequency depends on the grid demand, and it can be varied by simply varying the current density ramping rate. The mode switching frequency may affect the transient behavior heavily. A parametric study on the influence of the mode switching frequency was conducted, and the results are presented here. A dimensionless parameter of mode switching frequency $\left(R_{f}\right)$ was proposed as follows:

$$
R_{f}=\frac{f}{f_{0}}
$$

where $f_{0}$ is the original switching mode frequency adopted in the experimental stack testing, where $f_{0}=2.510^{-5}$ $\mathrm{Hz}(1 / 40000 \mathrm{~s})$.

Fig. 9 illustrates the profiles of the model output parameters with different $R_{f}$ values. With $R_{f}$ increasing from 1.0 to 4.0, the maximum temperature variation $\Delta T_{\mathrm{s}}$ decreases from $15 \mathrm{~K}$ to $5 \mathrm{~K}$. However, the peak value of $\left|\frac{d T_{\mathrm{s}}}{d \tau}\right|$ remains the same. This finding shows that the main factor affecting $\left|\frac{d T_{s}}{d \tau}\right|$ is $I . R_{f}$ slightly influences the stack voltage. The peak value of $V_{\mathrm{s}}$ decreases from $8.45 \mathrm{~V}$ to $8.30 \mathrm{~V}$ in the SOEC mode and increases from $7.25 \mathrm{~V}$ to $7.4 \mathrm{~V}$ in the SOFC mode. With increasing $R_{f}$, the direction of the electrochemical reactions revert more frequently. The work medium stored in the stack can be refilled in time. As shown in Fig. 9(e), the fluctuation of $u_{\mathrm{H}_{2}}$ becomes less with increasing $R_{f}$. Figs. 9 (d) and 9(f) show the plot of the power consumption and generation $(\dot{W})$ during mode switching processes and the reversible efficiency ( $\eta_{\mathrm{re}}$ ) of the SOC stack with different $R_{f}$ values. The frequency influences the reversible efficiency indirectly. As shown in Fig. 9 (a), at $4 \mathrm{~T}_{0}$, the final stack temperature $T_{\mathrm{s}}$ decreases with increasing $R_{f}$. The increasing in the mode switching frequency benefits the stack works in a relatively narrow range temperature. The peak values of $V_{\mathrm{s}}$ reduce in the SOEC mode, and the minimum values of $V_{\mathrm{s}}$ increase in the SOFC mode. In other words, for an identical mode switching cycle, the required power for electrolysis reduces and the generated electricity increases. This phenomenon can explain why the reversible efficiency increases with $R_{f}$. 


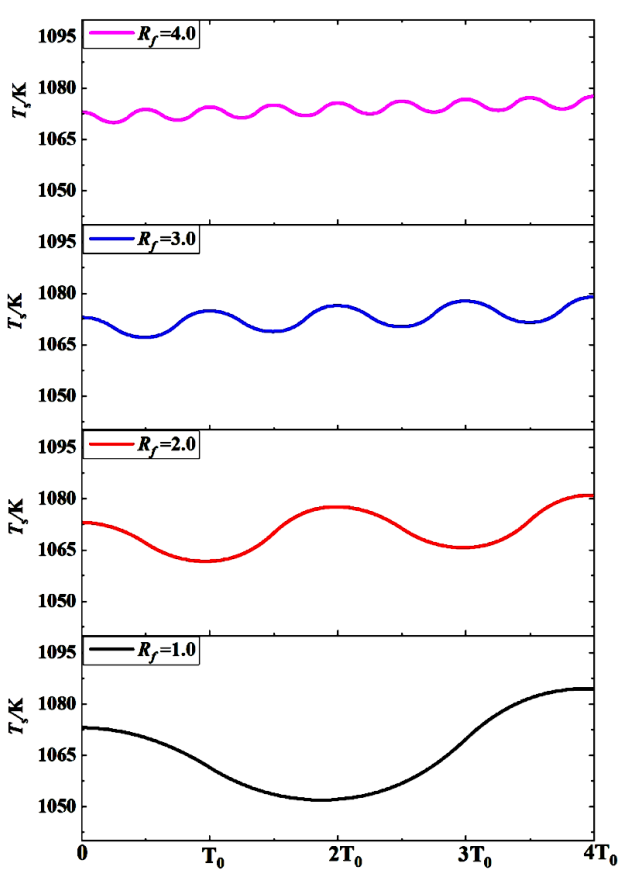

(a)

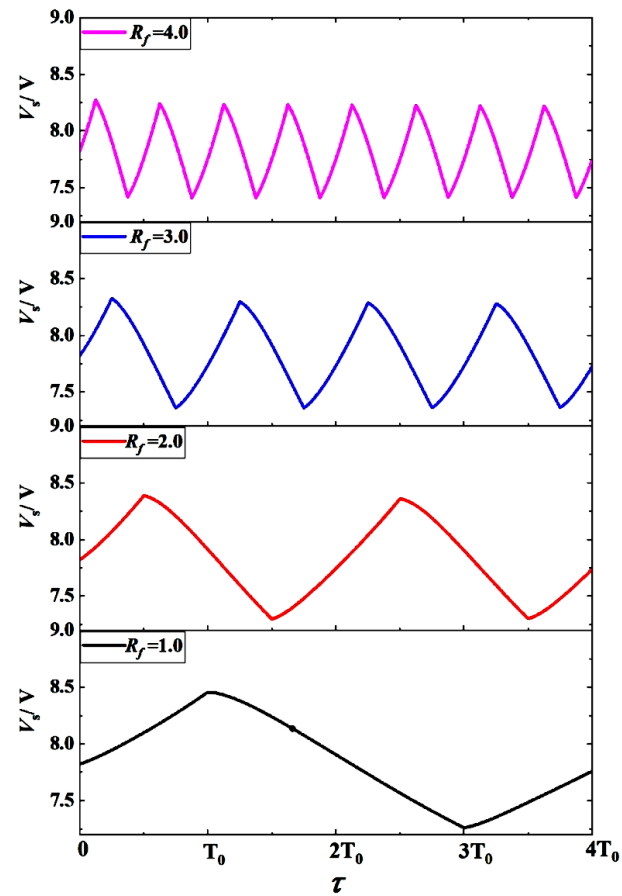

(c)

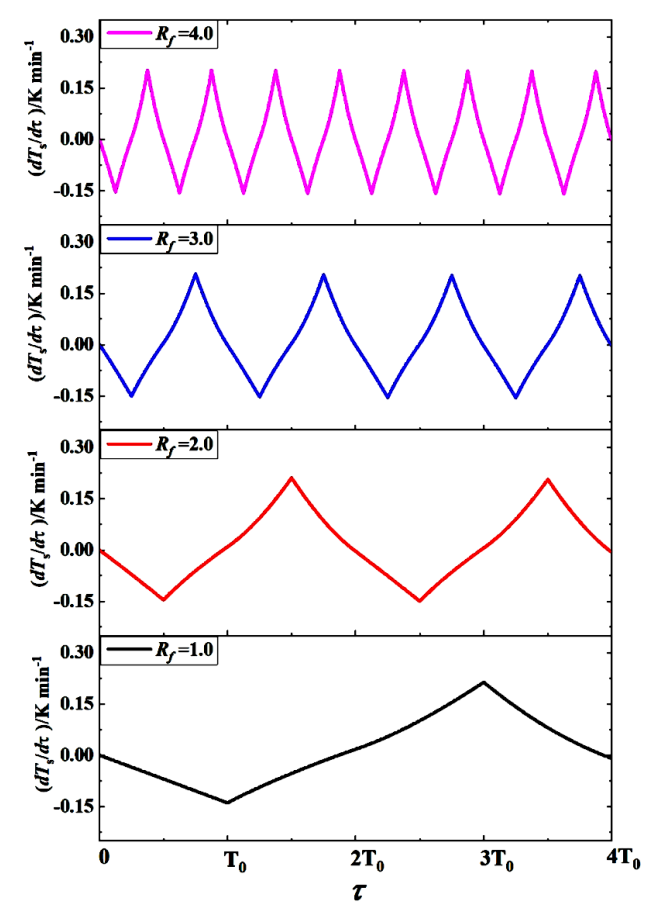

(b)

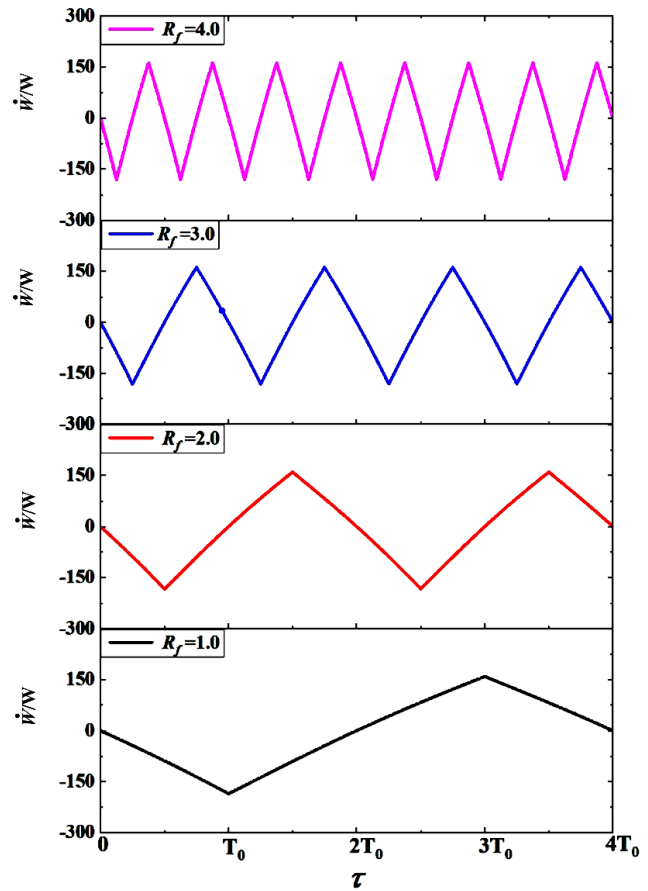

(d) 


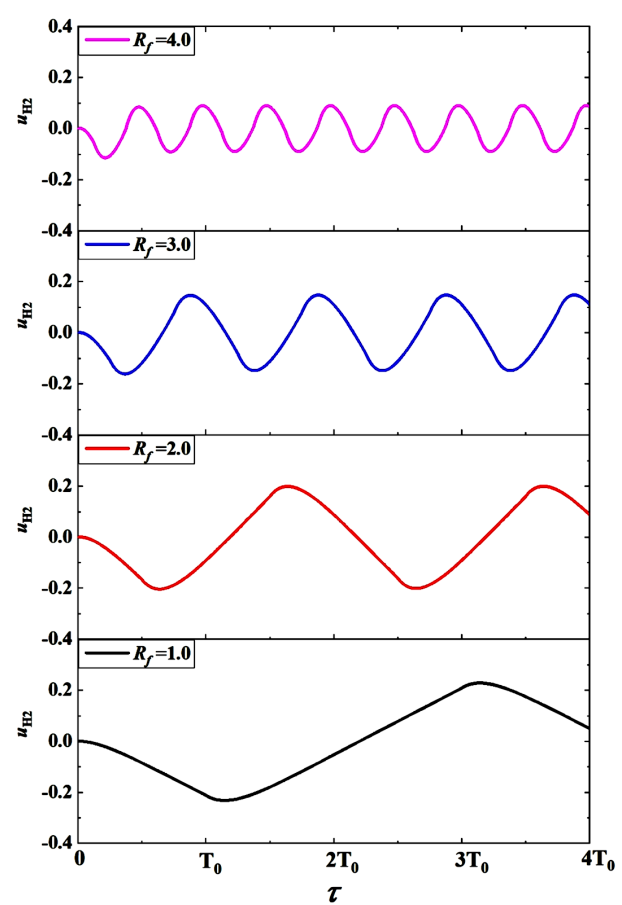

(e)

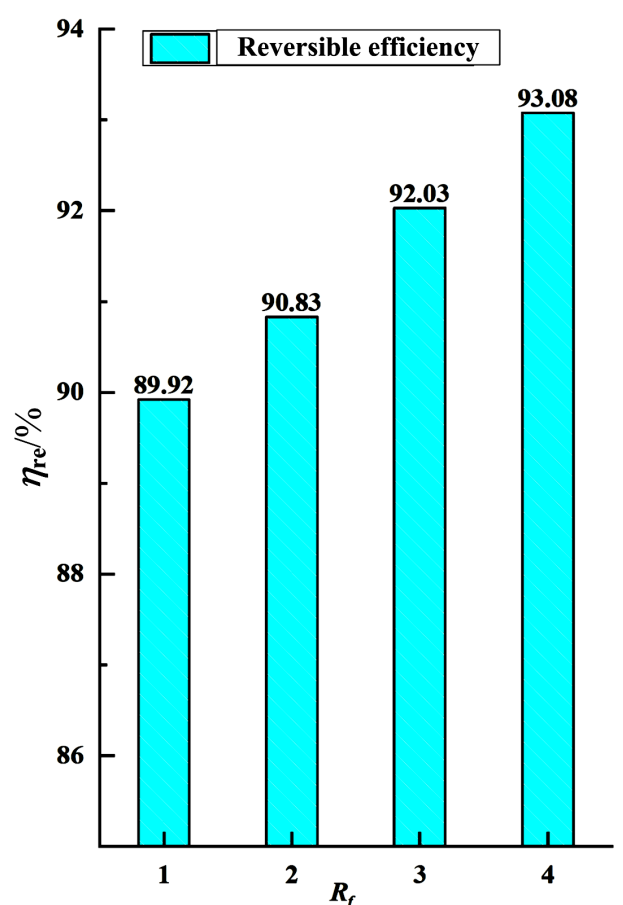

(f)

Fig. 9 (a) Temperature, (b) temperature variation rate, (c) voltage, (d) power, (e) fuel utilization, and (f) reversible efficiency of the stack with different $R_{f}$

\subsection{Stack heat capacity $\left(C_{\mathrm{s}}\right)$}

The product of the stack specific heat capacity $\left(c_{\mathrm{s}}\right)$ and the stack mass $\left(M_{\mathrm{s}}\right)$ is the stack heat capacity $\left(C_{\mathrm{s}}\right)$. Here, a parametric study on $C_{\mathrm{s}}$ was conducted, and the results are plotted in Fig. 10. A dimensionless parameter of $R_{C \mathrm{~s}}$ was introduced as follows:

$$
R_{C \mathrm{~s}}=\frac{c_{\mathrm{s}} M_{\mathrm{s}}}{c_{\mathrm{s}, 0} M_{\mathrm{s}, 0}}
$$

where $c_{\mathrm{s}, 0}$ and $M_{\mathrm{s}, 0}$ are the original specific heat capacity and mass of the stack, respectively, as listed in Table 3 .

During mode switching transient processes, the stack thermal state may be affected by $R_{C s}$. Electrochemical reactions occur in the stack, and $T_{\mathrm{s}}$ greatly influences the physical and chemical properties of the work medium.

With increase in $R_{C \mathrm{~s}}$ from 1.0 to 4.0 , the maximum stack-temperature variation $\Delta T_{\mathrm{s}}$ decreases from 32 to $8 \mathrm{~K}$. The increase in $R_{C \mathrm{~s}}$ also reduces $\left|\frac{d T_{\mathrm{s}}}{d \tau}\right|$ significantly. To extend the stack lifetime, increasing $R_{C \mathrm{~s}}$ may contribute to alleviating the fatigue due to thermal cycling especially in adiabatic environment. The influence of $R_{C \mathrm{~s}}$ on $V_{\mathrm{s}}$ is not significant, as shown in Fig. 10(c). Figs. 10(f) and 10h) present an enlarged view of $\dot{W}$ at peak values. As depicted 
in Fig. 10(e), a slight difference is observed in $u_{\mathrm{H}_{2}}$ with different $R_{C \mathrm{~s}}$ values. The stack thermal states are affected by $R_{C \mathrm{~s}}$, thus possibly affecting the molar quantity of the stored work medium in the stack (according to the ideal gas equation). The $u_{\mathrm{H}_{2}}$ value is determined by the difference between the inlet and outlet fuel flow rates (molar quantity of stored gases in the stack). The change in $\Delta T_{\mathrm{s}}$ may slightly influence the stored work medium molar quantity. Therefore, the difference in $u_{\mathrm{H}_{2}}$ is negligible. As shown in Fig. 10(c), with the increasing in $R_{C \mathrm{~s}}$ from 1.0 to $4.0, V_{\mathrm{s}}$ decreases obviously in the SOEC mode, and the minimum values are very close for different $R_{\mathrm{Cs}}$ values. Results show that less power is needed in electrolysis mode, and the stack can generate nearly identical electricity in the fuel cell mode. This is the mainly reason for $\eta_{\mathrm{re}}$ increasing from $89.92 \%$ to $90.39 \%$ with $R_{\mathrm{Cs}}$ from 1.0 to 4.0 . In total, increasing stack heat capacity can reduce the stack temperature variation rate and improve the reversible efficiency of the energy-conversion processes.

$$
\multimap R_{C \mathrm{~s}}=1.0 \multimap R_{C \mathrm{~s}}=2.0 \multimap R_{C \mathrm{~s}}=3.0 \multimap R_{C \mathrm{~s}}=4.0
$$

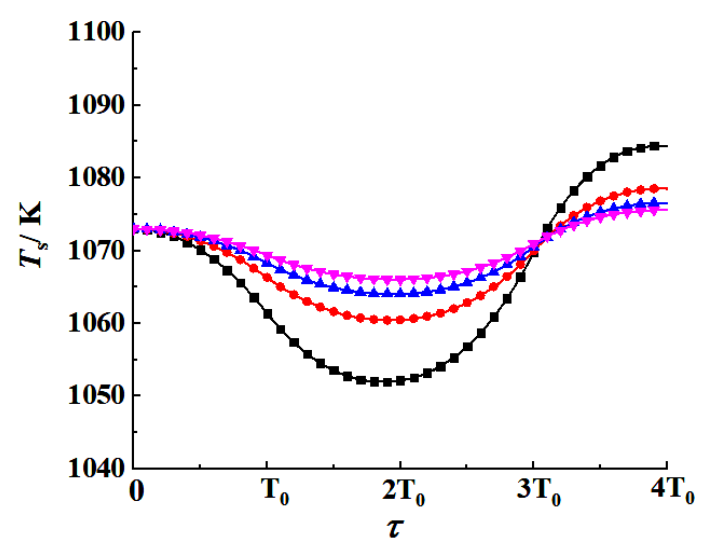

(a)

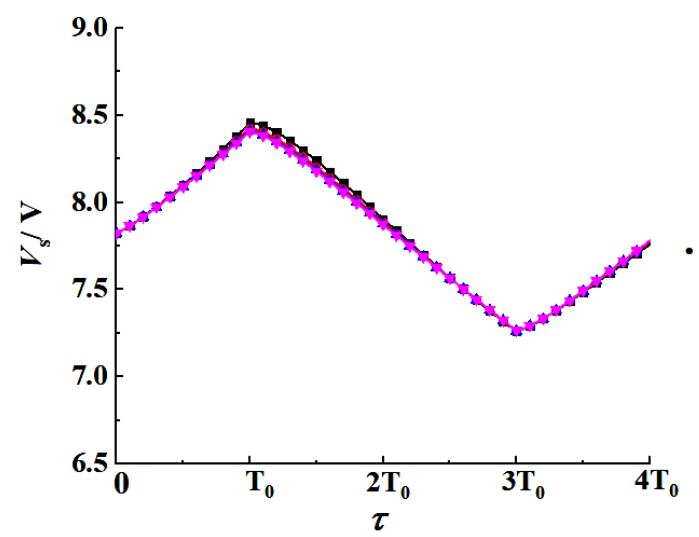

(c)

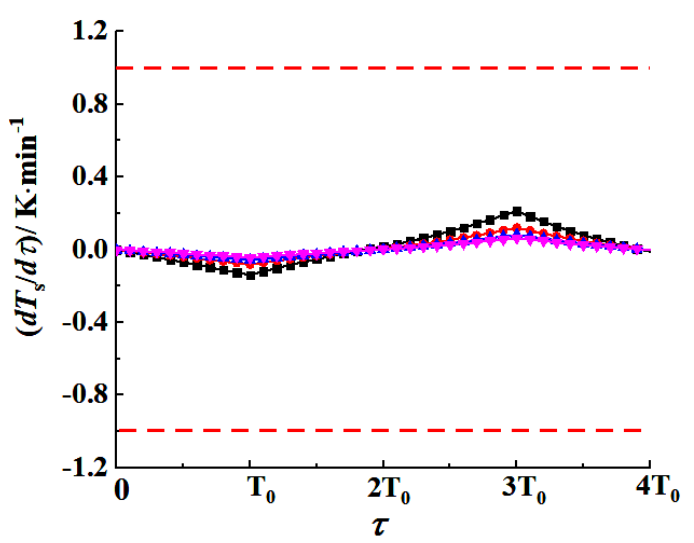

(b)

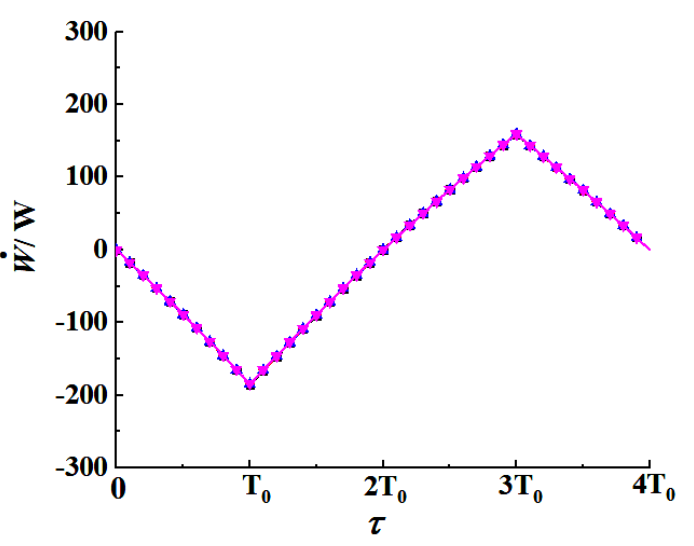

(d) 


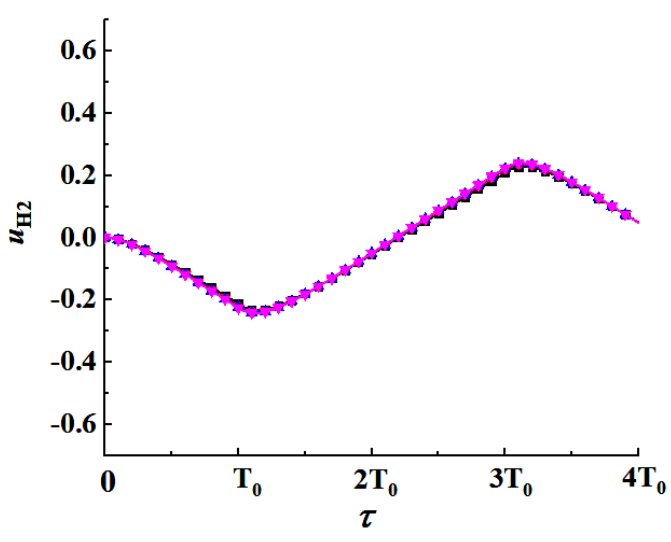

(e)

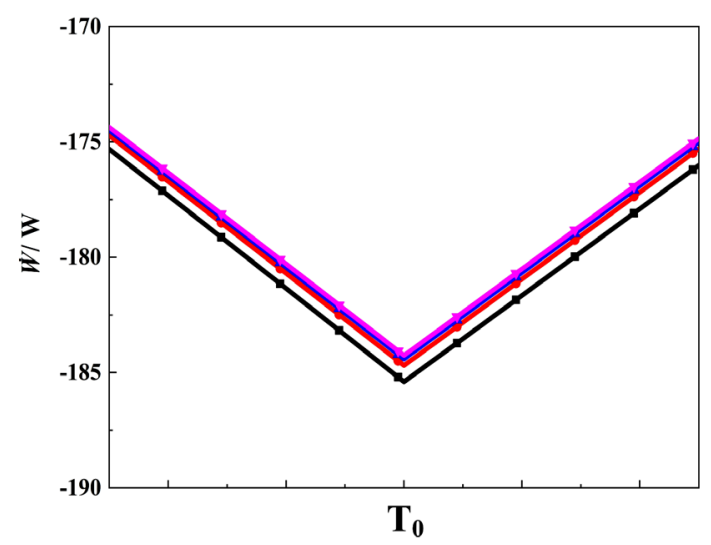

(g)

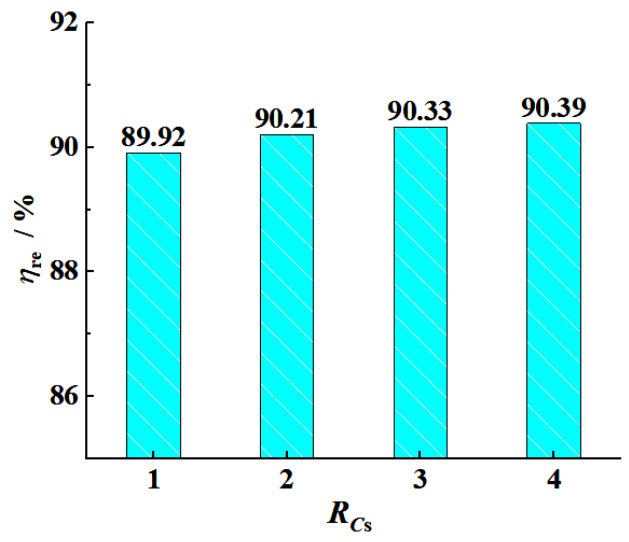

(f)

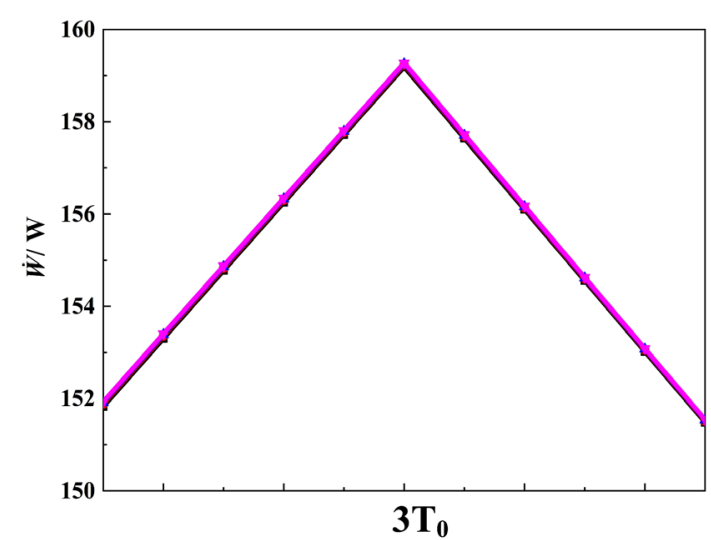

(h)

Fig. 10 (a) Temperature, (b) temperature variation rate, (c) voltage, (d) power, (e) fuel utilization, (f) reversible efficiency, and (g), (h) enlarged view of $\dot{W}$ of the stack with different $R_{C \mathrm{~s}}$

In this section, we have conducted a detailed parameter study on a number of stack operating and design parameters, including the fuel fraction of the inlet gas, the inlet gas temperature, the stack operation pressure, the current density, the mode switching frequency, and the stack heat capacity. The stack transient performance during mode switching from SOEC mode to SOFC mode in the adiabatic environment was explored. The results and the discussions focus on the SOC stack only, i.e. not taking into account the BOP components and the durability of the SOC stacks. For example, an optimum inlet gas temperature depends on not only the stack transient performance, but also the lifetime and cost of stack components and BOP components, where the latter may play a more important role. Increasing the stack operation pressure reduces stack temperature variation and hence increases the reversible efficiency of the SOC stacks, but also adds complexity into the reversible system and may not necessarily increase the system efficiency. Further work is needed to extend our current study to the system level, which is ongoing and the results will be presented in our future work. 


\section{Conclusions}

A dynamic model of the SOC stack based on the lumped parameter method was developed and validated with experimental data. Based on this model, the effects of representative factors on the SOC transient performance during mode switching processes in an adiabatic environment were explored via an extensive parametric study. The main conclusions of this study are as follows.

1) With the increasing of $x_{\mathrm{H}_{2}}$ from 0.2 to 0.6 (while keeping other parameters constant), the temperature fluctuation range $\left(\Delta T_{\mathrm{s}}\right)$ and the temperature variation rate $\left(\left|\frac{d T_{\mathrm{s}}}{d \tau}\right|\right)$ decrease by $25 \%$. $V_{\mathrm{s}}$ increases by $10 \%$, and the increase in $\eta_{\mathrm{re}}$ is $2.91 \%$.

2) The inlet work medium temperature $\left(T_{\text {in }}\right)$ affects the thermal status of the stack during the transient processes. With $T_{\text {in }}$ increasing from $973 \mathrm{~K}$ to $1273 \mathrm{~K}, \Delta T_{\mathrm{s}}$ decreases to some extent, but the maximum value of $\left|\frac{d T_{\mathrm{s}}}{d \tau}\right|$ decreases by approximately $30 \%$. In the SOEC mode, the peak voltage of $V_{\mathrm{s}}$ decreases from $9.9 \mathrm{~V}$ to $7.8 \mathrm{~V}$, whereas in SOFC mode, the minimum value of $V_{\mathrm{s}}$ increases from $6.5 \mathrm{~V}$ to $7.0 \mathrm{~V}$. $\eta_{\mathrm{re}}$ increases by $13.13 \%$.

3) With dimensionless stack pressure $\left(R_{p}\right)$ increasing from 1.0 to $4.0, \Delta T_{\mathrm{s}}$ decreases from $32 \mathrm{~K}$ to $24 \mathrm{~K}$, $\left|\frac{d T_{\mathrm{s}}}{d \tau}\right|$ decreases by $25 \%, V_{\mathrm{s}}$ increases by $0.5 \%$, and $\eta_{\text {re }}$ increases by $1.8 \%$.

4) With the dimensionless current density $\left(R_{\mathrm{I}}\right)$ increasing from 0.5 to $3.0, \Delta T_{\mathrm{s}}$ increases from $15 \mathrm{~K}$ to $120 \mathrm{~K}$, and the maximum value of $\left|\frac{d T_{\mathrm{s}}}{d \tau}\right|$ increases by nearly 10 times. The variation range of $V_{\mathrm{s}}$ also increases significantly. $\eta_{\mathrm{re}}$ decreases by $25.3 \%$.

5) With the dimensionless mode switching frequency $\left(R_{f}\right)$ increasing from 1.0 to 4.0 , the variation range of $T_{\mathrm{s}}$ decreases from $15 \mathrm{~K}$ to $5 \mathrm{~K}$. The variation range of $\left|\frac{d T_{s}}{d \tau}\right|$ remains almost unchanged. The maximum value of $V_{\mathrm{s}}$ decreases by $1.7 \%$ (SOEC), the minimum value increases by $2.0 \%$ (SOFC), $\eta_{\text {re }}$ increases with $R_{f}$ and the maximum difference is $3.16 \%$.

6) With the dimensionless heat capacity of the stack $\left(R_{C \mathrm{~S}}\right)$ increasing from 1.0 to $4.0, \Delta T_{\mathrm{s}}$ decreases from $32 \mathrm{~K}$ to $8 \mathrm{~K}$, and $\left|\frac{d T_{\mathrm{s}}}{d \tau}\right|$ decreases accordingly. $V_{\mathrm{s}}$ is almost unaffected, and $\eta_{\mathrm{re}}$ increases from $89.92 \%$ to $90.39 \%$.

In summary, to reduce stack-temperature variation and hence extend the stack operational life, larger heat capacity of the stack and higher hydrogen molar fraction $\left(x_{\mathrm{H}_{2}}\right)$ of fuel electrode feed gases are proposed. From a stack point of view, higher operation pressure and lower current density are beneficial for increasing the reversible efficiency. 


\section{Nomenclature}

\section{Abbreviations}

$\begin{array}{ll}A S R & \text { area specific resistance } \\ B O P & \text { balance of plant } \\ \text { SOC } & \text { solid-oxide cells } \\ \text { SOEC } & \text { solid-oxide electrolysis cell } \\ \text { SOFC } & \text { solid-oxide fuel cell } \\ S R U & \text { single repeating unit } \\ T P B & \text { three phases boundary }\end{array}$

\section{Greek symbols}

$\tau$

time

$\eta$

efficiency

\section{Subscript}

Cs

f

$f$

I

in

out

$p$

re

S

0 heat capacity of the stack

furnace

switching frequency

current density

inlet value

outlet value

pressure

reversible efficiency

stack

initial value

\section{References}

[1] Luo Y, Wu X-y, Shi Y, Ghoniem AF, Cai N. Exergy analysis of an integrated solid oxide electrolysis cell-methanation reactor for renewable energy storage. Applied Energy. 2018;215:371-83.

[2] Gmbh S. Gesetz Fur Den Vorrang Erneuerbarer Energien (Erneuerbare-Energien-Gesetz - Eeg). 2017.

[3] Wang J, You S, Zong Y, Cai H, Træholt C, Dong ZY. Investigation of real-time flexibility of combined heat and power plants in district heating applications. Applied Energy. 2019;237:196-209.

[4] Wang C, Zhao Y, Liu M, Qiao Y, Chong D, Yan J. Peak shaving operational optimization of supercritical coal-fired power plants by revising control strategy for water-fuel ratio. Applied Energy. 2018;216:212-23.

[5] Wang C, Qiao Y, Liu M, Zhao Y, Yan J. Enhancing peak shaving capability by optimizing reheat-steam temperature control of a double-reheat boiler. Applied Energy. 2020;260. 
[6] Luo X, Wang J, Dooner M, Clarke J. Overview of current development in electrical energy storage technologies and the application potential in power system operation. Applied Energy. 2015;137:511-36.

[7] Kazempoor P, Braun RJ. Model validation and performance analysis of regenerative solid oxide cells for energy storage applications: Reversible operation. International Journal of Hydrogen Energy. 2014;39:5955-71.

[8] Kazempoor P, Braun RJ. Model validation and performance analysis of regenerative solid oxide cells: Electrolytic operation. International Journal of Hydrogen Energy. 2014;39:2669-84.

[9] Wang L, Chen M, Küngas R, Lin T-E, Diethelm S, Maréchal F, et al. Power-to-fuels via solid-oxide electrolyzer: Operating window and techno-economics. Renewable and Sustainable Energy Reviews. 2019;110:174-87.

[10] Ovtar S, Tong X, Bentzen JJ, Thyden KTS, Simonsen SB, Chen M. Boosting the performance and durability of Ni/YSZ cathode for hydrogen production at high current densities via decoration with nano-sized electrocatalysts. Nanoscale. 2019;11:4394-406.

[11] Hjalmarsson P, Sun X, Liu Y-L, Chen M. Durability of high performance Ni-yttria stabilized zirconia supported solid oxide electrolysis cells at high current density. Journal of Power Sources. 2014;262:316-22.

[12] Irvine JTS, Neagu D, Verbraeken MC, Chatzichristodoulou C, Graves C, Mogensen MB. Evolution of the electrochemical interface in high-temperature fuel cells and electrolysers. Nature Energy. 2016;1.

[13] Salogni A, Colonna P. Modeling of solid oxide fuel cells for dynamic simulations of integrated systems. Applied Thermal Engineering. 2010;30:464-77.

[14] Khadem-Hamedani B, Yaghmaei S, Fattahi M, Mashayekhan S, Hosseini-Ardali SM. Mathematical modeling of a slurry bubble column reactor for hydrodesulfurization of diesel fuel: Single- and two-bubble configurations. Chemical Engineering Research and Design. 2015;100:362-76.

[15] Papari S, Kazemeini M, Fattahi M, Fatahi M. Dme Direct Synthesis from Syngas in a Large-Scale Three-Phase Slurry Bubble Column Reactor: Transient Modeling. Chemical Engineering Communications. 2014;201:612-34.

[16] Bao C, Wang Y, Feng D, Jiang Z, Zhang X. Macroscopic modeling of solid oxide fuel cell (SOFC) and model-based control of SOFC and gas turbine hybrid system. Progress in Energy and Combustion Science. 2018;66:83-140.

[17] Hauck M, Herrmann S, Spliethoff H. Simulation of a reversible SOFC with Aspen Plus. International Journal of Hydrogen Energy. 2017;42:10329-40.

[18] S.Srikanth MPH, S.Gupt, K.A.Friedrich. Transient reversible solid oxide cell reactor operation - Experimentally validated modeling and analysis. Applied Energy. 2018;232:473-88.

[19] Zheng Y, Luo Y, Shi Y, Cai N. Dynamic Processes of Mode Switching in Reversible Solid Oxide Fuel Cells. Journal of Energy Engineering. 2017;143.

[20] Ni M. 2D thermal-fluid modeling and parametric analysis of a planar solid oxide fuel cell. Energy Conversion and Management. 2010;51:714-21.

[21] Ni M. 2D thermal modeling of a solid oxide electrolyzer cell (SOEC) for syngas production by H2O/CO2 co-electrolysis. International Journal of Hydrogen Energy. 2012;37:6389-99.

[22] Bhattacharyya D, Rengaswamy R, Finnerty C. Dynamic modeling and validation studies of a tubular solid oxide fuel cell. Chemical Engineering Science. 2009;64:2158-72.

[23] Nikooyeh K, Jeje AA, Hill JM. 3D modeling of anode-supported planar SOFC with internal reforming of methane. Journal of Power Sources. 2007;171:601-9.

[24] Peksen M, Al-Masri A, Blum L, Stolten D. 3D transient thermomechanical behaviour of a full scale SOFC short stack. International Journal of Hydrogen Energy. 2013;38:4099-107.

[25] Chen B, Xu H, Tan P, Zhang Y, Xu X, Cai W, et al. Thermal modelling of ethanol-fuelled Solid Oxide Fuel Cells. Applied Energy. 2019;237:476-86.

[26] Qu Z, Aravind PV, Boksteen SZ, Dekker NJJ, Janssen AHH, Woudstra N, et al. Three-dimensional computational fluid dynamics modeling of anode-supported planar SOFC. International Journal of Hydrogen Energy. 2011;36:10209-20. 
[27] Al-Masri A, Peksen M, Blum L, Stolten D. A 3D CFD model for predicting the temperature distribution in a full scale APU SOFC short stack under transient operating conditions. Applied Energy. 2014;135:539-47.

[28] Zhang Z, Yue D, Yang G, Chen J, Zheng Y, Miao H, et al. Three-dimensional CFD modeling of transport phenomena in multi-channel anode-supported planar SOFCs. International Journal of Heat and Mass Transfer. 2015;84:942-54.

[29] Nerat M, Juričić $Đ$. A comprehensive 3-D modeling of a single planar solid oxide fuel cell. International Journal of Hydrogen Energy. 2016;41:3613-27.

[30] Nishida RT, Beale SB, Pharoah JG, de Haart LGJ, Blum L. Three-dimensional computational fluid dynamics modelling and experimental validation of the Jülich Mark-F solid oxide fuel cell stack. Journal of Power Sources. 2018;373:203-10.

[31] Cheng T, Jiang J, Wu X, Li X, Xu M, Deng Z, et al. Application oriented multiple-objective optimization, analysis and comparison of solid oxide fuel cell systems with different configurations. Applied Energy. 2019;235:914-29.

[32] Safari A, Shahsavari H, Salehi J. A mathematical model of SOFC power plant for dynamic simulation of multi-machine power systems. Energy. 2018;149:397-413.

[33] Perna A, Minutillo M, Jannelli E, Cigolotti V, Nam SW, Yoon KJ. Performance assessment of a hybrid SOFC/MGT cogeneration power plant fed by syngas from a biomass down-draft gasifier. Applied Energy. 2018;227:80-91.

[34] Navasa M, Graves C, Chatzichristodoulou C, Løye Skafte T, Sundén B, Lund Frandsen H. A three dimensional multiphysics model of a solid oxide electrochemical cell: A tool for understanding degradation. International Journal of Hydrogen Energy. 2018;43:11913-31.

[35] Liu L, Kim G-Y, Chandra A. Modeling of thermal stresses and lifetime prediction of planar solid oxide fuel cell under thermal cycling conditions. Journal of Power Sources. 2010;195:2310-8.

[36] Wen H, Ordonez JC, Vargas JVC. Single solid oxide fuel cell modeling and optimization. Journal of Power Sources. 2011;196:7519-32.

[37] Wen H, Ordonez JC, Vargas JVC. Optimization of single SOFC structural design for maximum power. Applied Thermal Engineering. 2013;50:12-25.

[38] Li Y, Shen J, Lu J. Constrained model predictive control of a solid oxide fuel cell based on genetic optimization. Journal of Power Sources. 2011;196:5873-80.

[39] Bang-Møller C, Rokni M, Elmegaard B. Exergy analysis and optimization of a biomass gasification, solid oxide fuel cell and micro gas turbine hybrid system. Energy. 2011;36:4740-52.

[40] Habibollahzade A, Gholamian E, Behzadi A. Multi-objective optimization and comparative performance analysis of hybrid biomass-based solid oxide fuel cell/solid oxide electrolyzer cell/gas turbine using different gasification agents. Applied Energy. 2019;233-234:985-1002.

[41] Jin X, Xue X. Mathematical modeling analysis of regenerative solid oxide fuel cells in switching mode conditions. Journal of Power Sources. 2010;195:6652-8.

[42] Wendel CH, Braun RJ. Design and techno-economic analysis of high efficiency reversible solid oxide cell systems for distributed energy storage. Applied Energy. 2016;172:118-31.

[43] Menon V, Janardhanan VM, Deutschmann O. A mathematical model to analyze solid oxide electrolyzer cells (SOECs) for hydrogen production. Chemical Engineering Science. 2014;110:83-93.

[44] Santhanam S, Heddrich MP, Riedel M, Friedrich KA. Theoretical and experimental study of Reversible Solid Oxide Cell (r-SOC) systems for energy storage. Energy. 2017;141:202-14.

[45] Huangfu Y, Gao F, Abbas-Turki A, Bouquain D, Miraoui A. Transient dynamic and modeling parameter sensitivity analysis of 1D solid oxide fuel cell model. Energy Conversion \& Management. 2013;71:172-85.

[46] R O'hayre SC, FB Prinz, W Colella Fuel cell fundamentals. 2nd ed Hoboken, New Jersey: John Wiley \& Sons. 2009.

[47] Fu Y, Jiang Y, Poizeau S, Dutta A, Mohanram A, Pietras JD, et al. Multicomponent Gas Diffusion in Porous Electrodes. Journal of The Electrochemical Society. 2015;162:F613-F21.

[48] Hajimolana SA, Hussain MA, Daud WMAW, Soroush M, Shamiri A. Mathematical modeling of solid oxide fuel cells: A 
review. Renewable and Sustainable Energy Reviews. 2011;15:1893-917.

[49] Suwanwarangkul R, Croiset E, Fowler MW, Douglas PL, Entchev E, Douglas MA. Performance comparison of Fick's, dusty-gas and Stefan-Maxwell models to predict the concentration overpotential of a SOFC anode. Journal of Power Sources. 2003;122:9-18.

[50] Bhattacharyya D, Rengaswamy R. A Review of Solid Oxide Fuel Cell (SOFC) Dynamic Models. Ind Eng Chem Res. 2009;48:6068-86.

[51] Noren DA, Hoffman MA. Clarifying the Butler-Volmer equation and related approximations for calculating activation losses in solid oxide fuel cell models. Journal of Power Sources. 2005;152:175-81.

[52] Solheim A. In SOFC micromodelling, an international energy agency SOFC task report. Swiss Federal Office of Energy Brene.1992. p. 9.

[53] K GVKSKMMHMDS. VDI-Wärmeatlas. 10th ed Berlin: Springer. 2002.

[54] Banerjee A, Wang Y, Diercks J, Deutschmann O. Hierarchical modeling of solid oxide cells and stacks producing syngas via $\mathrm{H} 2 \mathrm{O} / \mathrm{CO} 2$ Co-electrolysis for industrial applications. Applied Energy. 2018;230:996-1013.

[55] Hendriksen KAMCPBRKPV. Long-term operation of a solid oxide cell stack for coelectrolysis of steam and $\mathrm{CO} 2$. Proceedings of 12th European SOFC \&amp; SOE Forum, Lucerne, Switzerland. 2016; :A0804

[56] Kungas R, Blennow P, Heiredal-Clausen T, Norby TH, Rass-Hansen J, Primdahl S. Systematic Lifetime Testing of Stacks in CO2 Electrolysis. Ecs Transactions. 2017;78:2895-905.

[57] Stoeckl B, Subotić V, Reichholf D, Schroettner H, Hochenauer C. Extensive analysis of large planar SOFC: Operation with humidified methane and carbon monoxide to examine carbon deposition based degradation. Electrochimica Acta. 2017;256:325-36.

[58] Wang Y, Banerjee A, Deutschmann O. Dynamic behavior and control strategy study of $\mathrm{CO} 2 / \mathrm{H} 2 \mathrm{O}$ co-electrolysis in solid oxide electrolysis cells. Journal of Power Sources. 2019;412:255-64. 